\title{
Deactivation mechanisms of atmospheric plasma spraying Raney
}

\section{nickel electrodes.}

Daniel Chade $^{\mathrm{a}}$, Leonard Berlouis ${ }^{\mathrm{b}}$, David Infield ${ }^{\mathrm{c}}$, Peter Tommy Nielsen ${ }^{\mathrm{d}}$, Troels Mathiesen ${ }^{\mathrm{e}}$

${ }^{a}$ Renewable Energy Technology Group, Institute for Energy and Environment, Department of Electronic and Electrical Engineering, University of Strathclyde, 204 George Street, Glasgow G1 1XW, United Kingdom, daniel.chade@, strath.ac.uk

${ }^{b}$ WestCHEM, Department of Pure and Applied Chemistry, University of Strathclyde, 295 Cathedral Street, G1 1XL Glasgow, United Kingdom, 1.berlouis@strath.ac.uk

${ }^{c}$ Renewable Energy Technology Group, Institute for Energy and Environment, Department of Electronic and Electrical Engineering, University of Strathclyde, 204 George Street, Glasgow G1 1XW, United Kingdom, david.infield@strath.ac.uk ${ }^{\mathrm{d} F o r c e ~ T e c h n o l o g y, ~ P a r k ~ A l l e ́ ~ 345, ~} 2605$ Brondby, Denmark, ptn@,force.dk eForce Technology, Park Allé 345, 2605 Brondby, Denmark, trm@,force.dk 


\begin{abstract}
:
Major current research trends in alkaline electrolysis are targeted towards improving efficiency, extending the durability and decreasing the price of the electrolyser units. The novel atmospheric plasma spraying (APS) production method for Raney nickel coatings demonstrated good efficiency for the hydrogen evolution reaction (HER). The research work performed focused on the investigation of the degradation/deactivation mechanisms of these APS electrodes. The formation of hydrides was recognised as a key contributor towards cathode deactivation and to prevent it, in-situ activation in the electrolyte as well as hydrides oxidation, through controlled switching of the cell potential were carried out. Both techniques showed some effect in suppressing the deactivation process but failed to eliminate it completely. The APS Raney nickel cathodes also presented good stability for variable load operations during the cycling.
\end{abstract}

\title{
Keywords:
}

Alkaline electrolyser, hydrogen, Raney nickel, degradation mechanisms, electrocatalyst

\section{Introduction}

Long term, variable load operation is one of the major challenges that need to be faced by electrolysers. Achieving the highest performance over as long period of time as possible was always a key criterion, but today's electrolysers are additionally aimed to operate with highly time variable renewable energy sources. This particular application necessitates the need for electrolyser durability under highly variable load environments. 
Current literature does not appear to provide adequate information on the degradation issues relating to such operation of commercial alkaline electrolysers. Indeed, only one, publicly available research work dealing directly with this issue has been identified. The doctoral dissertation and associated paper of A. Bergen [1], [2] investigated the effects of variable power and intermittent operation on the low-pressure Stuart SRA $6 \mathrm{~kW}$ electrolyser. In these experiments, it was observed that an intermittent load had a negative impact on the electrolyser efficiency. Its performance decreased during operation when a full shut-down was instigated in each cycle. This was not found for uninterrupted operation or operation where the device was kept at a minimum holding current of 10 A. Additionally, it was observed that after turning off the device, there was a marked fall in the voltage over time before it stabilised at a much lower value. The paper concluded that the introduction of control techniques, such as that of a minimum holding current as well as a rest period could minimise the deterioration in the electrolyser performance.

The findings of Bergen at al. [1], [2] were partially confirmed by data from Hydrogenics [3] where it was shown that although the electrolyser still suffered from degradation effects on intermittent load operation, the impact on performance was reduced if certain procedures were followed. The Hydrogenics electrolyser, operated under constant current mode, saw an increase in the voltage of the electrolyser with the number of on/off cycles performed. The data indicated that after 10,000 cycles ( over 200 days of operation), the performance dropped by only around 7\%. In comparison, the Stuart SRA demonstrated higher degradation over a period of 8 hours of intermittent operation. It is well known that until recently, when the new generation of devices were designed to overcome this particular issue, alkaline electrolysers did not operate efficiently with variable load. Hydrogenics might be considered as a successor to the Stuart technology as the two companies merged in 2004 [4]. In this 
respect therefore, the data from the Stuart SRA $6 \mathrm{~kW}$ represents the previous generation of alkaline electrolysers which were not particular designed or suited for intermittent load operation.

Although available data on actual commercial alkaline electrolysers is very limited, the degradation issues of the electrodes have been analysed more widely in peer-reviewed literature [5], [6], [7], [8], [9], [10], [11], [12], [13], [14], [15], [16]. A large number of alkaline electrolysers use nickel or its alloys as electrodes [17], [18]. Hence, an examination of the degradation effects that occur on the various nickel electrodes types could extend our knowledge about the processes that occur inside the commercial electrolyser units.

As noted above, one of the most widely reported concerns about electrode degradation is the deactivation of the nickel cathode due to hydrides formation. Hydride creation on the electrode surface during the hydrogen evolution reaction (HER) is considered to be responsible for building a diffusion barrier for hydrogen atoms [9], [10], [11], [12], [13]. This normally results in increasing both activation and ohmic losses and leads to a significant reduction in the cathode performance over time. To prevent this hydride formation, several methods have been proposed, including the application of iron coatings on the electrode surface [8]; addition of compounds of vanadium [10], [11] or molybdenum [12] into electrolyte and oxidation of the created hydrides by a controlled increase of the applied potential to a pre-determined level [13].

Another degradation issue reported is that associated with the intermittent operation of the electrolyser. Some research publications have stated that when the electrolyser was left unpolarised for a certain period, it exhibited a lower performance on restarting. Divisek et al. 
[13], [14] in their work described this characteristic on Raney nickel electrodes when aluminium or zinc was present within the electrode structure. When the electrolyser was left un-polarised, both aluminium and zinc were prone to electrochemical corrosion. They indicated that if the aluminium or zinc content within electrode dropped below a certain level, the electrocatalytic activity towards HER decreased, with a concomitant increase in the cathodic overpotential and consequently, a reduction in the electrolyser performance. That work also mentioned that a lowering of the temperature of operation of the electrolyser unit could lead to the degradation of the cathode catalyst due to extended hydrides formation under these conditions [14].

On the other hand Schiller et al. [15], [16], demonstrated that it was possible to manufacture Raney nickel electrodes using vacuum plasma spraying (VPS) that were resistant to both hydrides deactivation and intermittent load operation effects. This work is particularly relevant as the VPS method is closely related to that of atmospheric plasma spraying (APS), under investigation here. However, the VPS technique requires more sophisticated equipment for the electrode manufacturing process. They demonstrated that their electrodes, used in a 10 $\mathrm{kW}$ electrolyser suffered minimal degradation following long term $(15,000$ hours $)$, variable load operation.

Atmospheric plasma sprayed (APS) Raney nickel electrodes produced by Force Technology have shown very good initial performance with regard to the hydrogen evolution reaction [19], [20]. However, their stability against degradation effects on operation over long time periods and in variable load environments is still to be established. The understanding of all the phenomena responsible for the degradation of the electrodes surfaces towards HER is 
critical in order to enable electrode improvements to be carried out and so lead to technological commercialisation of the process.

\section{System setup and experimental arrangement}

The electrodes samples manufacturing process, similarly as the configuration of the system and all the applied experimental procedures are described in detail elsewhere [19] [20].

The samples were manufactured using commercially available APS equipment: Sulzer Metco multicoat system. The APS system used 3M torch that was mounted on a robot programmed for x.y motion. Additionally a Spray Watch 3i plume analyser was used to minimise material waste and shorten the magnitude of trials. Raney Nickel for the samples was 50/50 nickel/aluminium with $-90 \sim+45 \mu \mathrm{m}$ particle size interval, that was deposited on $0.5 \mathrm{~mm}$ thick nickel plate [20].

Electrochemical control and data acquisition employed either Solartron 1287/1250 electrochemical interface/frequency response analyser, controlled by CorrWARE software or SP-150 electrochemical interface with a 10 A current booster, with EC-lab controlling software. IR compensation based on current interrupt was applied for all potentiostatic/potentiodynamic experiments and its value was set to $85 \%$. As a reference electrode, mercury/mercuric oxide was employed $\left(E^{\circ}=0.0984 \mathrm{~V} v s\right.$ SHE$)$ and platinumbased mesh was used as a counter electrode which active area exceeded $1 \mathrm{~cm}^{2}$. During conducted experiments Raney nickel electrode active faced into counter electrode. All the work was carried out using the APS samples with $100 \mu \mathrm{m}$ Raney nickel (50/50 nickel/aluminium) catalyst thickness in the alkaline electrolyte at a temperature of $70^{\circ} \mathrm{C}$, 
unless otherwise stated. The $100 \mu \mathrm{m}$ was an intermediate thickness in comparison to the 30 $\mu \mathrm{m}$ and $300 \mu \mathrm{m}$ versions (that were also tested during experimental work) and it was characterised by the best performance for HER. The samples obtained from Force Technology consisted of $100 \mathrm{~mm} \times 100 \mathrm{~mm} \times 0.5 \mathrm{~mm}$ plates covered on both sides with Raney nickel catalyst. From the plates, smaller samples of $1 \mathrm{~cm} \times 1 \mathrm{~cm}$ dimension, square shape were cut and used as the working electrodes during the experiments. Subsequently one side of each sample was soldered to an electrical wire that provided electrical contact indispensable for a connection to potentionstat. This non active side of the electrode was then insulated using epoxy resin Araldite 2022. Proper covering of the back surface and electrical contact was critical to avoid contamination of the electrolyte solution with components from the solder and wire material. All the electrodes were initially activated using the procedure described in ref. [19], namely all the samples were immersed in $30 \% \mathrm{KOH}$ and $10 \mathrm{wt} \%$ sodium/potassium tartrate solution at $80^{\circ} \mathrm{C}$ for 24 hours. The aim of this process was to leach out most of the aluminium from the intermetallic phases and also make the electrode surface porous [19], [20]. The cross sections of sprayed and activated Ni-Al coating are presented in Figure 1.

As well as the standard 3 electrode configuration used to investigate the properties of the cathode, a two-compartment pyrex electrolyser connected together by a glass flange was employed in the study used for single cell electrolyser investigation described in the last part of Results and discussion section. Each of the compartments was surrounded by an outer jacket through which the water was pumped from an external reservoir to control the temperature of the electrolyte. The internal volume of each compartment was $c a .310 \mathrm{~cm}^{3}$. To operate at elevated temperatures, the vessels were heated by water delivered from a Gallenkamp Thermo Stirrer 100 water bath. A polymer diaphragm made of Celgard 3501 was 
placed between the two compartments and its role was to prevent the mixing of the gases and at the same time allow ionic conductivity between the anodic and cathodic chambers. Both chambers were well stirred using magnetic stirrers to avoid concentration gradients during the electrolysis. The vessels were covered with plastic lids with cavities through which the electrodes were inserted.

\section{Results and discussion}

\subsection{Stable load operation and the impact of hydride formation}

During the operation of the activated electrode under constant load, it was observed that over a period of a few hours, there was a gradual decrease in the electrode's performance. Figure 2 shows this increase in the cathode potential for the HER of the $100 \mu \mathrm{m}$ sample, operating at a constant current density of $300 \mathrm{~mA} / \mathrm{cm}^{2}$ over a period of 24 hours. Immediately following this operation, the electrode response was examined using cyclic voltammetry, polarization curves and EIS techniques. Another 24 hours of constant current operation was again applied after these tests. At the start of this $2^{\text {nd }}$ cycle, the electrode performance appeared to have partially recovered in that the cathodic potential for HER was now much lower than at the end of the $1^{\text {st }}$ cycle. However, there was then a very rapid fall in electrode performance (compared to that in the $1^{\text {st }}$ cycle) and after 6 hours of operation, the cathodic potential reached a value of $-1.5 \mathrm{~V}$. Indeed, similar results were obtained when operating the $30 \mu \mathrm{m}$ and $300 \mu \mathrm{m}$ electrode samples under different current densities [19].

The observed deactivation effect here could be ascribed to hydrogen absorption into the metal lattice and leading to the formation of a $\beta$-nickel hydride phase [7], [11], [12], which 
corresponds to a change in the $\mathrm{H} / \mathrm{Ni}$ atomic ratio from $\leq 0.1$, to $\geq 0.6[11],[21]$. The formation of the hydride phase is considered to change the $d$-character of the nickel to $s p$ character by filling the $d$-band. The $s p$-character of the hydride is similar to that of silver or copper which are less active towards HER than fresh nickel [11]. In Figure 2, two distinct regions can be observed. The first one, a gradual increase in the cathodic electrode potential is found over the time period up to 15 hours $(54000 \mathrm{~s})$ on the first cycle and could be attributed to the absorption of hydrogen by the electrode whereas in the second feature, beyond this, the increase is less dramatic and corresponds to the formation of the $\beta$-hydride [11]. The regeneration of the electrode's performance at the start of the second cycle could have occurred due to the oxidation of the hydrides that would have taken place when potential was subjected to values more positive than $-0.9 \mathrm{~V}$ during the $\mathrm{CV}$, polarization curves and EIS investigations at the end of the first $24 \mathrm{~h}$ cycle.

It is also worth noting that similar behaviour was observed during the testing of the different samples from all the available APS catalysts thicknesses (30,100 and $300 \mu \mathrm{m})$. The general trend found was that the deactivation process took longer for samples with higher surface areas. This phenomenon can be explained by the fact it is the geometrical area that is used to evaluate the current density employed in the electrolysis. However, because of the porous nature of the activated Raney nickel surfaces, the larger sample areas would in fact be subjected to a lower local current densities and so, the surface concentration of adsorbed $\mathrm{H}$ atoms, a precursor to hydride formation, would be lower. Correspondingly, the process time for hydride deactivation also increased when smaller current values were used in the electrolysis experiments. 
Due to the cathode deactivation issue, several methods were investigated in order to counteract this effect. This involved (i) a controlled oxidation of the cathode in which the potential was moved to more positive values for a set period of time; (ii) a process of in-situ activation involving the addition of compounds of molybdenum and vanadium to the electrolyte during the activation process and (iii) a hybrid method of combining the electrolyte activation process with the hydrides oxidation method.

The data from Figure 2 indicated that the APS electrodes were highly prone to deactivation by hydrides formation. The first method attempted in minimising this impact was that of hydrides oxidation. The fundamentals of this oxidation process are based on the phenomenon that when the electrode potential is increased beyond $-0.9 \mathrm{~V}$, the hydrogen incorporated in the nickel oxidises back into the electrolyte solution [9]. Such an operation however, requires special control strategies for the electrolyser so as to oxidise and remove only the hydrides and so restore performance, but not the catalyst. On the other hand, it has been reported that such repeated oxidation and reduction (during normal electrolyser operation) introduces strain within the catalyst material, which could lead to mechanical failure [9].

Initially, the oxidation method was tested in a multiple cycle operation where each sample was operated under a current density of $0.3 \mathrm{~A} / \mathrm{cm}^{2}$ for 30 minutes after which, the potential was set to $-0.85 \mathrm{~V}$ for a $60 \mathrm{~s}$ period in order to oxidise the hydrides. This sequence was repeated 33 times. As can be seen from Figure $3(A)$, this did not give the desired effect which apart from the $1^{\text {st }}$ two cycles, the electrode performance decreased with every subsequent cycle. However, it did lead in each of the loadings to an initial lowering of the cathodic potential for the HER as the potential was always better than final value achieved in the previous cycle. Clearly then, the oxidation potential at $-0.85 \mathrm{~V}$ was inadequate to 
completely restore the electrode performance. Figure 3(B), shows the oxidation current response obtained for the potential step to $-0.85 \mathrm{~V}$ for some representative cycles. The initial high current spike can be attributed to the double-layer capacitance charging current, induced by the step voltage change, which would be quite significant on this electrode with a large surface area. The current density then stabilised at around $10 \mathrm{~mA} \mathrm{~cm}^{-2}$ after $\sim 15 \mathrm{~s}$, which was attributed mainly to hydrides removal effect although the oxidation of adsorbed hydrogen cannot be ruled out. As can be seen, this current density did not vary significantly between the cycles.

Due to the inadequate hydrides removal during this first series of experiments, it was decided to increase the oxidation potential up to $-0.2 \mathrm{~V}$ but at the same time reduce the oxidation period to $5 \mathrm{~s}$. This potential was considered positive enough to force all the hydrides to react, but the reduced time would prevent the formation of surface oxides on the Raney nickel electrode. The results presented in Figure 4(A) show that such a strategy did restore the system performance, at least after the first two oxidation cycles, yielding electrode potentials very similar to the starting value of $-1.21 \mathrm{~V}$ (Figure $3(A)$ ). For the subsequent cycles, although evidence from the potential step current profile suggested that the hydrides layer was completely removed, there was nevertheless a gradual decrease in the performance of the electrode. This was possibly caused by damage to the catalyst surface due to the high oxidation currents (Figure $4(B)$ ) during the potential step. Unfortunately due to too low sampling rate set for that experiment, detailed shape of current decay was not registered however, on Figure 4(B) it can be seen that electrical current density value was at least equal to $2.5 \mathrm{~A} / \mathrm{cm}^{2}$. Here it should be noted that APS electrodes were designed for nominal current density of $0.3 \mathrm{~A} / \mathrm{cm}$. This test also showed that during variable load operation, step voltage changes should be avoided as it can induce very high currents densities from the discharge of 
double layer capacitance. Also, the high surface area electrodes employ catalyst coatings, which are less physically stable than uniform material such as nickel or stainless steel plates.

Further experiments were carried out in which various oxidation regimes were tested and these included: short/long duration; high/low currents and different intervals between the cycles. Two main issues were identified after performing such tests. The first was that of insufficient hydrides removal and the second was degradation of the catalysts, if the oxidation process was not controlled. Despite running numerous tests on different samples, none of the procedures showed satisfactory results with regards to completely removing hydrides without damaging the catalyst surface.

The catalyst degradation due to over-oxidation was confirmed by cyclic voltammetry and by electrochemical impedance spectroscopy analyses. The fundamentals of the CV analysis was based on the phenomenon that the charge associated with $\mathrm{Ni}(\mathrm{OH})_{2}$ formation is proportional to the sample electrochemical active area. Here, the sample was polarised for 20 hours under a current density of $-200 \mathrm{~mA} / \mathrm{cm}^{2}$ and at the end of each hour, the sample was oxidised for 1 minute at the potential of $-0.85 \mathrm{~V}$. Following this, the cyclic voltammetry method was employed in which the potential was scanned from -1.05 to $0 \mathrm{~V}$ and back, at a $50 \mathrm{mV} / \mathrm{s}$ scan rate (Figure $5(A)$ ). The oxidation peak at $-0.5 \mathrm{~V}$ vs $\mathrm{Hg} / \mathrm{HgO}$ observed in the cyclic voltammogram and associated with $\mathrm{Ni}(\mathrm{OH})_{2}$ monolayer formation [22] was becoming smaller with every subsequent cycle which might be associated with the drop of performance Figure 5(A). As the charge under the peak is proportional to the electrochemical surface area, it thus shows that within each cycle, the active area was decreasing. This indicates that the oxidation which occurs at the potential of $-0.85 \mathrm{~V}$ can be detrimental to sample structure and 
its use should be minimised or very careful controlled in order to prevent possible sample damage when working with the APS Raney nickel electrodes.

Additional evidence for this degradation of catalyst structure as an effect of hydrides overoxidation was obtained from EIS measurements. During the first 24 hours, the sample was again operated under current density of $-200 \mathrm{~mA} / \mathrm{cm}^{2}$ and every hour, the electrolysis reaction was interrupted by an oxidation event, carried out here using a $0.3 \mathrm{~A} / \mathrm{cm}^{2}$ current density for one minute duration. After the first 24 hours operation period, the oxidation procedure was changed, namely current density was decreased to $0.2 \mathrm{~A} / \mathrm{cm}^{2}$ and the oxidation process took place until the voltage reached the value of $-0.2 \mathrm{~V}$. EIS analyses were performed at the start of the series of experiments and after 24 and 48 hours. Each time, they were preceded by $\mathrm{CV}$ and $j(V)$ curve analysis. Figure 6 shows the $j(V)$ curves obtained at these times and the magnitudes of the double layer capacitance and charge transfer resistance obtained from the EIS measurements and analyses are presented in Table 1. Charge transfer resistance and double layer capacitance were calculated according to the same method, which was described in the previous work [19]. Briefly Nyquist plot for investigated electrodes consists of two constant phase element semicircles, whereas higher frequency one is associated with electrode porous structure and lower frequency one depends on double layer capacitance and charge transfer resistance [22]. Not surprisingly, the $j(V)$ curves showed a significant drop in the performance after every sequence. Confirmatory data for this was also observed in the change of the EIS parameters shown in Table 1 and examples of Nyquist plots for $-1.05 \mathrm{~V}$ vs $\mathrm{Hg} / \mathrm{HgO}$ potential are visible in Figure 7. Here it should be emphasized that only low frequency is visible as it overlaps with high frequency one. 
The table shows the expended trend in the charge transfer resistance and double layer capacitance values with increasing negative potential as the electron transfer kinetics increases. Following the first $24 \mathrm{~h}$ of operation, it can be seen that at any given potential, there is a significant reduction in the double layer capacitance value and an increase in the charge transfer resistance. After the second 24 hour cycle, the charge transfer resistance increased further but not the $\mathrm{C}_{\mathrm{dl}}$ values. This might suggest that during the first 24 hours, the catalyst structure was significantly degraded and the electrochemically active area decreased, which also caused values of $R_{c t}$ to increase. During second 24 hours, the active area of the electrode did not change significantly but the further aluminium promoter loss that occurred decreased the general electrocatalytic activity. Such an effect has been described by Divisek et al. [13], [14], and it might also be the reason for the increase in $\mathrm{C}_{\mathrm{dl}}$ at the potentials of -1.00 at $-1.05 \mathrm{~V}$ after the second 24 hours operation sequence. Thus, the lost of electrocatalytic activity would have resulted in a decrease in the reaction rate and concomitantly, the amount of bubbles produced at that overpotential. That could have effectively resulted in a smaller amount of blocked pores and so, an increase in the value of double layer capacitance [23]. The similarity in the values of $\mathrm{C}_{\mathrm{dl}}$ at the extreme potentials at $24 \mathrm{~h}$ and $48 \mathrm{~h}$ was because at lower overpotentials, only a very small amount of bubbles was produced whereas at high overpotentials, the surface was fully covered by bubbles.

Another method investigated in order to decrease the influence of hydride formation was that of carrying out the activation of the APS electrodes in electrolytes containing compounds of vanadium, molybdenum or iron [8], [10], [11], [12], [24], [25], [26], [27]. In these experiments, the compounds, vanadium oxide $\left(\mathrm{V}_{2} \mathrm{O}_{5}\right)$ and/or sodium molybdenum oxide dihydrate $\left(\mathrm{Na}_{2} \mathrm{MoO}_{4} \cdot 2 \mathrm{H}_{2} \mathrm{O}\right)$ were dissolved into the $\mathrm{KOH}$ electrolyte used for the electrolytic activation process. During cathodic polarisation, this normally results in the deposition of 
vanadium and molybdenum species onto the electrode surface which could serve to prevent the deactivation effect due to hydride formation [11], [12]. An additional advantage of using compounds of vanadium and molybdenum is that, they are reported to improve electrocatalytic properties in connection with nickel, which would result in a better cathode performances for the HER [14], [15], [24], [25].

The initial experiments with vanadium were performed by adding $200 \mathrm{mg} / 1$ into the $30 \%$ $\mathrm{KOH}$ solution, in accordance with the work of Abouatallah et al [11]. The results obtained (Figure 8) indicated that the presence of the vanadium, even up to concentrations of 1000 $\mathrm{mg} / \mathrm{L}$ did not have any major impact on the initial electrode performance, indicating that there was no increase in the electrocatalytic activity. The impact of vanadium on the activation was observed however during long term operation, where a significant reduction in the cathodic potential to $c a$. $-1.3 \mathrm{~V}$ (from $-1.5 \mathrm{~V}$ without vanadium Figure 2) could be seen. After each of the 24 hours cycles, the CV method was applied which resulted in some regeneration of the electrode performance (due to partial hydrides oxidation). As can be seen from the figure, the initial deactivation process during first cycle occurred over a much longer period than in the subsequent cycles. Before the $4^{\text {th }}$ cycle, an additional amount of vanadium oxide was added to the electrolyte resulting in an increase in its concentration to $400 \mathrm{mg} / \mathrm{L}$. Similarly, before $5^{\text {th }}$ cycle, the concentration was increased further to $1000 \mathrm{mg} / \mathrm{L}$. Surprisingly this last concentration did not appear to have reduced the impact of hydrides formation. During the $4^{\text {th }}$ cycle, some voltage fluctuations were observed and the cause for this is unknown but it is likely to be due to an instrumental artefact. Similar features were observed several times during the many measurements taken and it probably could have been caused by the magnetic stirrer, which could have changed the impact of $\mathrm{H}_{2}$ bubbles by inducing convection and mechanically moving them away from the electrode surface. The 
small offsets seen in the data between the final plateau values of different cycles comes from the absence of $I R$ compensation during the galvanostatic mode of operation. This effect should normally have an impact not exceeding $50 \mathrm{mV}$. It has to be noted however that current interrupt $I R$ compensation was always applied during $j(V)$ curve measurements.

The second compound used in this study and which has been shown to reduce hydrides formation was sodium molybdenum oxide. This was added at concentration of $10 \mathrm{mM} / \mathrm{L}$ to the $\mathrm{KOH}$ electrolyte. Experiments similar to those previously described by Huot et al. and Tasic et al. [12], [24], [25] were carried out, where in essence $\mathrm{NaMoO}_{4}$ in different concentrations was added to the $\mathrm{KOH}$ electrolyte to prevent hydrides formation impacting on the electrode performance. It was observed that the molybdenum had a very similar effect to the vanadium regarding hydrides inhibition over the first $24 \mathrm{~h}$ of operation. There was a gradual increase in the cathodic potential from the initial value of $-1.1 \mathrm{~V}$ to the plateau value of $-1.35 \mathrm{~V}$ by $\sim 19.5 \mathrm{~h}$. On subsequent cycles however, this cathodic polarisation occurred much more rapidly and it was completed within $\sim 2.2 \mathrm{~h}, 1.1 \mathrm{~h}$ and $<0.5 \mathrm{~h}$ for cycles 2,3 and 4 respectively. These effects are much more severe than were observed for the vanadium pentoxide addition and would suggest that the molybdenum compound was not as effective in negating the effect of hydride formation. An increase of molybdenum concentration to 20 $\mathrm{mM} / \mathrm{L}$ also failed to reduce this further. It would appear then that the addition of the vanadium and molybdenum to the electrolyte provided only limited initial protection against the hydride formation and its associated increase in polarisation for the HER. Further experimental work involving a combination of vanadium and molybdenum was carried out, but no significant reduction in the impact of hydrides was noted in the data. 
A comparison of the $j(V)$ curves for $100 \mu \mathrm{m}$ samples is presented in Figure 9, obtained after reaching the sample hydrides deactivation plateau value (as shown in Figure 8). The data shown in the figure were from operation in the pure $\mathrm{KOH}$ electrolyte and after addition of the vanadium and/or molybdenum compounds. During these measurements, current interrupt $I R$ compensation was applied, which thus eliminated the ohmic losses arising from the electrolyte between the working and reference electrodes. As can be seen, significant differences in performance were observed which confirmed the reduction in the hydrides deactivation effect on application of the in-situ electrolyte addition activation method. Indeed, the in-situ activation procedure was able to reduce the hydrogen overpotential by $0.2 \mathrm{~V}$. Additionally it was observed that at the higher current density limits, the electrodes activated in molybdenum were slightly superior to those activated with only vanadium. This is in accordance with literature which indicates that molybdenum with nickel showed better electrolytic properties than vanadium and nickel [24]. The best performance though was achieved using a combination of vanadium and molybdenum. It is worth noting that the potential difference between all samples (apart from that in pure $\mathrm{KOH})$ was small $(<15 \mathrm{mV}$ at $300 \mathrm{~mA} / \mathrm{cm}^{2}$ current density) and this small variation could have simply arisen from other factors such as trace electrolyte contamination, hydrides structure or sample surface mechanical condition. Thus, in order to precisely estimate the difference in the performance of activated samples, supplementary tests would need to be performed.

Additional tests were performed combining the methods of oxidation and $\mathrm{V}_{2} \mathrm{O}_{5}$ electrolyte addition to the $\mathrm{KOH}$ electrolyte. The initial experiment on the $300 \mu \mathrm{m}$ APS sample was carried out in the pure $\mathrm{KOH}$ solution at a current density of $-200 \mathrm{~mA} / \mathrm{cm}^{2}$ but after every 30 $\min$, there was a $1 \mathrm{~min}$ oxidation with a $200 \mathrm{~mA} / \mathrm{cm}^{2}$ current density. The data of Figure 10 (A) showed the usual performance drop within the 24 hours operation, with the cathode 
potential increasing to $-1.35 \mathrm{~V}$ and this was again attributed to deterioration of the catalyst. However, as Figure $10(B)$ shows, after the addition of $200 \mathrm{mg} / \mathrm{L}$ of $\mathrm{V}_{2} \mathrm{O}_{5}$, partial reactivation of the electrode performance was achieved. The figure indicates that in the presence of the $\mathrm{V}_{2} \mathrm{O}_{5}$, the voltage change during the 30 min of cathodic polarisation was drastically reduced and there was even a decrease in the cathode potential at the end the period. This trend can be explained by the fact that although the oxidation events were still causing some damage to the catalyst structure, the effect of deactivation from further hydrides formation was reduced.

\subsection{Variable load operation}

There have been a few recent reports detailing the negative influence of variable load operation on the performance of the electrodes in the alkaline electrolyser [13], [14], [27]. The intermittent load degradation mechanisms in these reports were mainly associated to hydrides decomposition when the electrode was left in an un-polarised state. Such a process was considered to cause a shift of the cathode rest potential towards positive values where compounds such as: aluminium, zinc and molybdenum within the Raney nickel electrode structure became more prone to corrosion [13], [14], [27]. It was essential therefore that the variable operation tests were also carried out on the APS Raney nickel electrodes in order to assess their performance under these operational conditions.

To investigate the impact of intermittent operation, the APS Raney nickel electrode was tested over a 48 hour period, employing cycles in which the sample was electrolysed at a current density of $-200 \mathrm{~mA} / \mathrm{cm}^{2}$ for 15 minutes and then subsequently left for 15 minutes completely depolarised, i.e. at the open circuit voltage. The results from this experiment are shown in Figure 11(A). The general trend observed from the data was that although there was 
a gradual increase in the over-potential of the electrode with cycling, a decrease in the cathode over-potential was observed over the first $14 \mathrm{~h}$ of operation. If indeed the increase in polarisation arises from hydrides formation, it would appear then that during the initial stages, the 15 min period at open circuit was sufficient to remove most (if not all) of the hydrides formed during cathodic polarisation. Clearly then, following this initial period, hydride removal was not completed as can be seen from the still rising OCP value towards the end of the 15 min period. This then leads to a concomitant decrease in the cathode polarisation voltage during electrolyser operation. Prior to and after these experiment, the polarization curves, preceded by the standard oxidation process, were recorded and these are shown in (Figure 11(B)). As can be seen, the difference between these two curves in the figure is quite small, $c a .5 \mathrm{mV}$, even at the current density of $300 \mathrm{~mA} \mathrm{~cm}{ }^{-2}$. This would suggest that apart from hydrides formation, no other process was significantly involved in reducing the electrode performance and it can be concluded that APS electrodes are well suited for intermittent operation.

It is also worth noting examining in more detail the shape of the voltage (time) curves generated at the beginning and towards the end of this particular study. As can be seen in Figure $12(A)$, the change in the open circuit potential is quite small $(<10 \mathrm{mV})$ over the 15 min period but for later cycles, the change that occurs is of the order of $50 \mathrm{mV}$ (Figure 12 (B)). It can also be observed that the initial OCP value is lower for the later cycles. This observation can be again connected with the impact of hydrides formation which decreases this initial cathode OCP [13]. On switching to OCP, the hydrides are gradually oxidised and so, the OCP potential increases with time. On the other hand, the hydrides decomposition process is also considered to cause the decomposition of the residual aluminium promoter which also increases the final OCP value attained [13], [27]. 


\subsection{Single cell electrolyser tests}

The results presented in this section show the data obtained from the testing of the APS electrodes inside a single cell electrolyser unit. The $100 \mu \mathrm{m}$ APS Raney nickel samples of 1 $\mathrm{cm}^{2}$ surface area were used in this study as the anode and cathode. The same chemical procedure for activation as previously described was employed for the cathode [19] but for the anode, this was operated for 14 hours in the OER region instead, under a $200 \mathrm{~mA} / \mathrm{cm}^{2}$ current density. The reasoning here was to avoid the hydrides formation that normally occurs during HER and could have led to damage of the catalyst surface structure when it was subsequently oxidised. Following their respective electrochemical activations, the voltages of the anode and cathode were measured as a function of applied current density and the data obtained are presented in Figure 13. The electrode potentials were -1.026 and $0.576 \mathrm{~V}$ (under a $300 \mathrm{~mA} / \mathrm{cm}^{2}$ current density) for cathode and anode, respectively. These results showed that there was little change in the cathode potential but the anode voltage increased by $c a .120 \mathrm{mV}$ over this current range, which could have arisen due to the change in activation procedure.

These two activated electrodes were placed inside the single cell electrolyser and the cell voltage as a function of current density during the operation of the electrolyser was measured (Figure 14). As can be seen from the figure, the initial performance of the system was slightly lower than that estimated solely from the difference between cathode and anode voltages measured individually in the 3-electrode cell. The difference between the measured and calculated data is smallest $(20 \mathrm{mV})$ at low current densities and the largest $(40 \mathrm{mV})$ at high current densities. The difference at low current densities might come from the fact that applied IR compensation method based on current interrupt was not able to completely eliminate the impact of ohmic losses and for the instruments used during experiments it was 
set to the value of $85 \%$. During testing of the single cell electrolyser, the ohmic losses were higher due to larger distance between the electrodes and application of Celgard 3501 membrane to separate both electrodes. Another possible reason for this difference might be that electrodes just after electrochemical activation are still prone to changes in the material structure. For example and as noted above, hydrides formation normally occurs on the cathode. However, other processes, yet to be investigated (and beyond the scope of this work) could also be occurring at the anode. In terms of larger difference at high current densities, this might come from gas bubbles formed at the electrodes can also dissolve in the electrolyte, that increases ohmic drop. Typically bubbles amount is directly proportional to the current applied. Thus, although $I R$ compensation (using the current interrupt method) was used in all the measurements, it is likely that the cell resistance values in the twocompartment cell would be varying quite substantially here and so, the voltage correction would be less accurate.

The single cell electrolyser was then operated at a constant current density of $200 \mathrm{~mA} / \mathrm{cm}^{2}$ for a first period of $>24$ hours followed by a second period of 18 hours. The data obtained are shown in Figure 15 (A). During the first 24 hours, the cell voltage gradually increased but during the second period of operation, it stayed pretty constant but at a much higher value. The sudden increases in the voltage seen at $\sim 68,000 \mathrm{~s}$ in both runs were probably caused by the movement of the electrodes which could have occurred during the replenishment of water into electrolyser. Clearly, the overall performance of the electrolyser unit decreased with time and this can be seen from Figure 15 (B) which compares the current-voltage curves of the electrolyser at the beginning of the experiments and after each of the runs performed. 
In order to see what impact the single cell operation had on the electrolyser performance, the electrolyser electrodes were dismounted from the electrolyser unit and the characteristics of the cathode were measured once again using the three electrode system configuration. The cathode performance had reduced in a very similar manner as in the experiments conducted previously and indicates that the conclusions drawn from the 3-electrode experiments were equally applicable here in the full electrolyser operation.

\section{Conclusions and summary}

The results obtained in this study on the APS Raney nickel electrodes have indicated that the cathodic performance was significantly impacted by hydrides formation at the negative electrode. Both chemical and electrochemical measures were employed in order to reduce this hydride formation but were met with limited success. In the case of in-situ electrolyte activation, there was a decrease in the cathodic plateau overpotential, but the overall decrease in the electrode performance was still significant. The different procedures employed involving electrochemical oxidation showed insufficient hydrides removal or caused structural damage to the electrode surface. There was some success however on using a combination of in-situ activation of the electrolyte through the addition of oxides of vanadium and/or molybdenum with electrochemical oxidation techniques. The APS Raney nickel electrodes here showed good stability under variable load operations with very good initial electrode potential values obtained during the cycling. Before further development of the technology for commercialisation, the deactivation effect needs to be examined further and brought under control. One of the ways of achieving this could be through the incorporation of molybdenum in the manufacturing process for the APS Raney nickel electrodes. 
Although the main aim of the experiments performed and reported here was focused on the performance of the APS cathodes, it is worth adding that to complete the work so as to fully understanding the electrolyser degradation phenomena, the performance of the APS electrodes for the oxygen evolution reaction would also have to be covered. This is however, beyond the scope of the present research. 
References:

1. A. Bergen, L. Pitt, A. Rowe, P. Wild, N. Djilali. Transient electrolyser response in a renewable-regenerative energy system. International Journal of Hydrogen Energy 34 (2009) pp. $64-70$

2. A. P. Bergen. Integration and Dynamics of a Renewable Regenerative Hydrogen Fuel Cell System. PhD studies dissertation. 2008 University of Victoria, Canada

3. Renewable Hydrogen by Electrolysis: Opportunities and Application. Renewable Hydrogen by Electrolysis: Opportunities and Applications NSERC Atlantic Canada Wind to Hydrogen Workshop Moncton, November 23, 2010, https://secure.itoolkit.com/www_chfca_ca/files/nserc_archambault.pdf, accessed $24^{\text {th }}$ October 2013

4. http://www.prnewswire.com/news-releases/hydrogenics-corporation-succeeds-in-bid-forstuart-energy-systems-corporation-66227987.html, accessed $24^{\text {th }}$ October 2013

5. B. Baranowski. Electrochemical formation of nickel hydride in alkaline solutions. Journal of Electroanalytical Chemistry, 472 (1999), pp. 182-184

6. D. M. Soares, O. Teschke, I. Torriani. Hydride effect on the kinetics of the hydrogen evolution reaction on nickel cathodes in alkaline media. Journal of Electrochemical Society, 139 (1992), pp. 98-105

7. H. E. G. Rommal, P. J. Morgan. The role of absorbed hydrogen on the voltage-time behaviour of nickel cathodes in hydrogen evolution. Journal of Electrochemical Society: Electrochemical Science and Technology (1988), pp. 343-346

8. A. E. Mauer, D. W. Kirk,S. J. Thorpe. The role of iron in the prevention of nickel electrode deactivation in alkaline electrolysis. Electrochimica Acta, 52 (2007), pp. 3505-3509

9. D. S. Hall, C. Bock, B. R. MacDougall. The electrochemistry of metallic nickel: oxides hydroxides, hydrides and alkaline hydrogen evolution. Journal of The Electrochemical Society, 160 (2013), pp. 235-243 
10. R. M. Abouatallah, D.W. Kirk, J.W. Graydon. Long-term electrolytic hydrogen permeation in nickel and the effect of vanadium species addition. Electrochimica Acta 47 (2002) pp. 2483-2494

11. R. M. Abouatallah, D.W. Kirk, S.J. Thorpe, J.W. Graydon. Reactivation of nickel cathodes by dissolved vanadium species during hydrogen evolution in alkaline media. Electrochimica Acta 47 (2001) 613-621

12. J. Y. Huot, L. Brossard. In situ activation by sodium molybdate on various metallic substrates, substrates during alkaline water electrolysis. International Journal of Hydrogen Energy, Vol. 14, No. 4, pp. 229-232, 1989

13. J. Divisek, B. Mergel, H. Schmitz. Advanced water electrolysis and catalyst stability under discontinuous operation. International Journal of Hydrogen Energy, Vol. 15, No. 2, pp. 105-114, 1990

14. J. Divisek, B. Steffen, H. Schmitz. Theoretical analysis and evaluation of the operating data of a bipolar water electrolyser. International Journal of Hydrogen Energy, Vol. 19, No. 7. pp. 579-586, 1994

15. G. Schiller, V. Borck. Vacuum plasma sprayed electrodes for advanced alkaline water electrolysis. International Journal of Hydrogen Energy, Vol. 17, No. 4 (1992). pp. 261-273

16. G. Schiller, R. Henne, P. Mohr, V. Peineckie. High performance electrodes for an advanced intermittently operated 10-kW alkaline water electrolyzer. International Journal of Hydrogen Energy, Vol. 23, No. 9 (1998). pp. 761-765

17. K. Zeng, D. Zhang. Recent progress in alkaline water electrolysis for hydrogen production and applications. Progress in Energy and Combustion Science, 36 (2010), pp. $307-326$

18. H. Wendt. Electrochemical Hydrogen Technologies. Electrochemical Production and Combustion of Hydrogen. Elsevier 1990 
19. D. Chade, L. Berlouis, D. Infield, A. Cruden, P. T. Nielsen, T. Mathiesen. Evaluation of Raney nickel electrodes prepared by atmospheric plasma spraying for alkaline water electrolysers. International Journal of Hydrogen Energy 38 (2013) pp. 14380-14390

20. P. T. Nielsen, T. Mathiesen, J. K. Kristensen, L. Hilbert, L. Yde. Atmospheric plasma spraying of electrodes for conversion of electricity to hydrogen by high temperature alkaline electrolysis of water. Proceedings of ITSC 2011, Sept. 27-29, Hamburg, Germany

21. M. L. Wayman, G.C. Weatherly, in: P. Nash (Ed.), Phase Diagrams of Binary Nickel Alloys, ASM International, Materials Park, OH, 1991, p. 155

22. V. Ganesh, V. Lakshminarayanan. Preparation of high surface area nickel electrodeposit using a liquid crystal template technique. Electrochimica Acta, 49 (2004), pp. 3561-3572

23. S. Rausch, H. Wendt. Morphology and utilization of smooth hydrogen-evolving raney nickel cathode coatings and porous sintered-nickel cathodes. Journal of the Electrochemical Society, 143 (1996), pp. 2852-2862.

24. G. S. Tasic, S. P. Maslovara, D. L. Zugic, A. D. Maksic, M. P. Marceta Kaninski. Characterization of the Ni-Mo catalyst formed in situ during hydrogen generation from alkaline water electrolysis. International Journal of Hydrogen Energy, No. 36 (2011). pp. $11588-11595$

25. M. P. M. Kaninski, D. P. Saponjic, V. M. Nikolic, D. L. Zugic, G. S. Tasic. Energy consumption and stability of the Ni-Mo electrodes for the alkaline hydrogen production at industrial conditions. International Journal of Hydrogen Energy, No. 36 (2011). pp. 88648868

26. J. Y. Huot, L. Brossard. Time dependence of the hydrogen discharge at $70^{\circ} \mathrm{C}$ on nickel cathodes. International Journal of Hydrogen Energy, Vol. 12, No. 12 (1987). pp. 821-830

27. W. Hu. Electrocatalytic properties of new electrocatalysts for hydrogen evolution in alkaline water electrolysis. International Journal of Hydrogen Energy 25 (2000) pp. 111-1 


\section{Figures:}

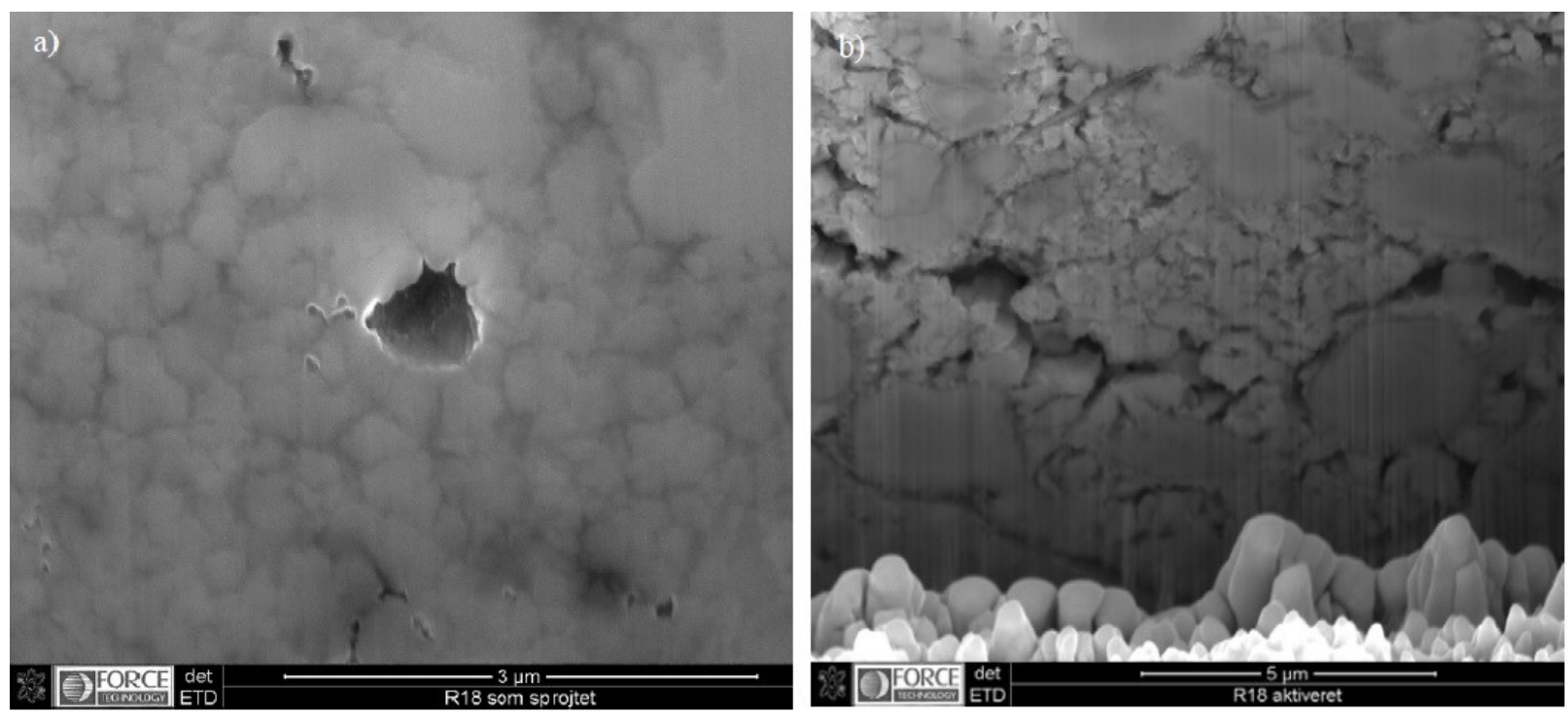

Figure 1. SEM pictures of cross-sections made by focused ion beam technique (FIB). As sprayed (a) and activated NiAl coating (b) [20] 


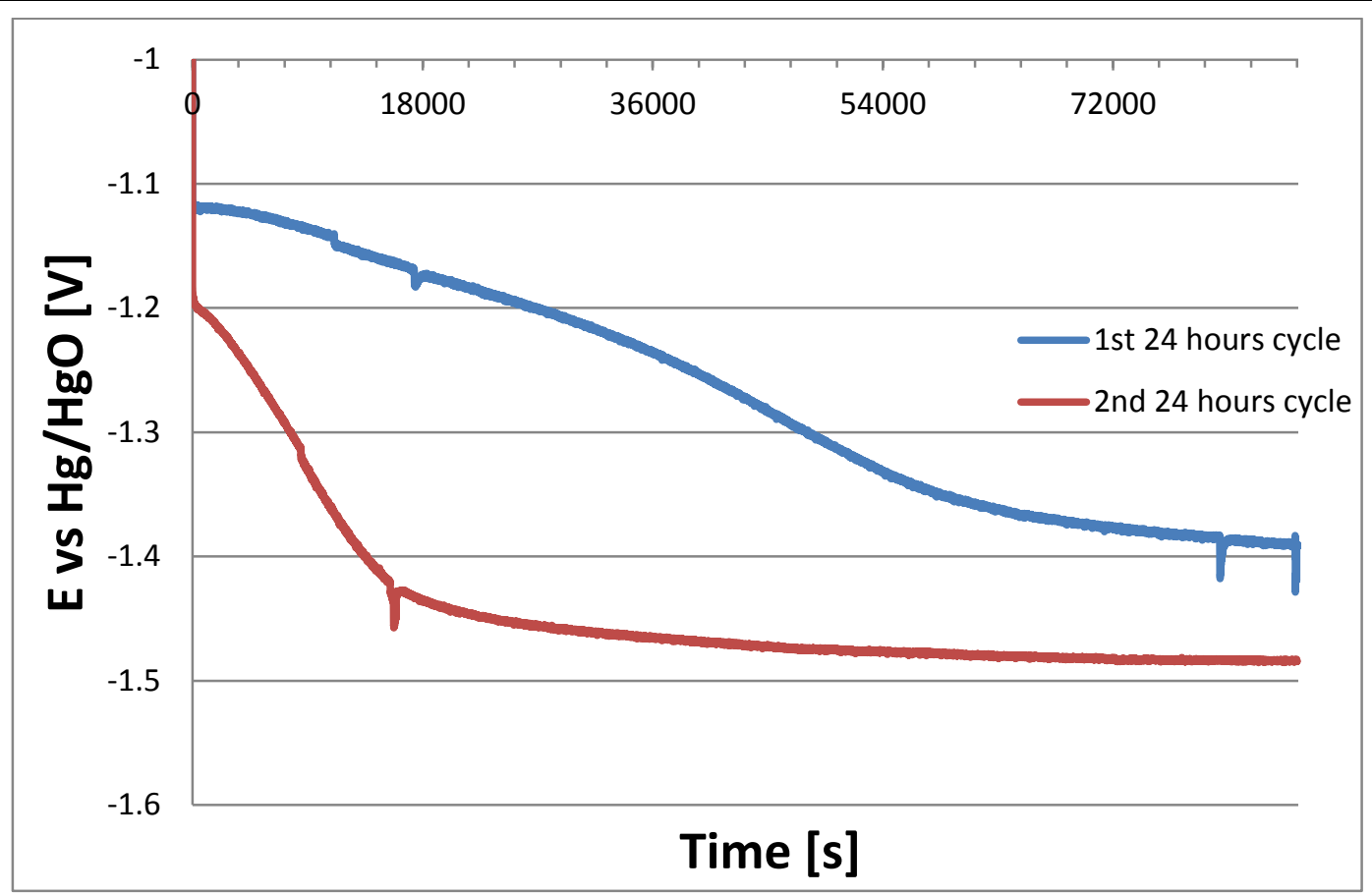

Figure 2. Deactivation of Raney nickel 100 um sample under constant load operation under constant current density of $300 \mathrm{~mA} / \mathrm{cm}^{2}$ 

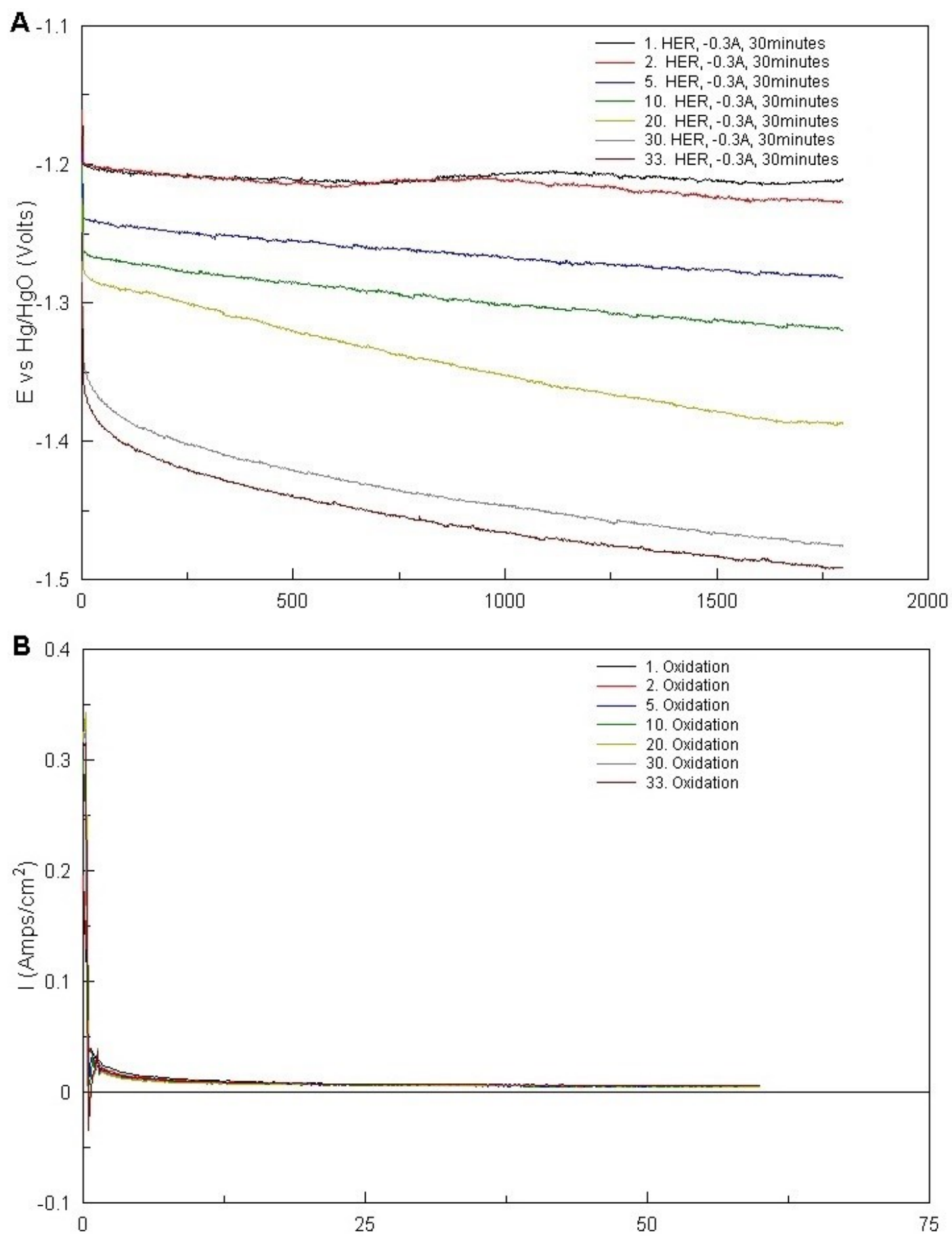

Figure 3. A - Operation of $100 \mu \mathrm{m}$ electrode sample under current density of $-0.3 \mathrm{~A} / \mathrm{cm}^{2}$,

within subsequent cycles separated with oxidation process, $B$ - Oxidation currents for every cycle under -0.85 Votential 

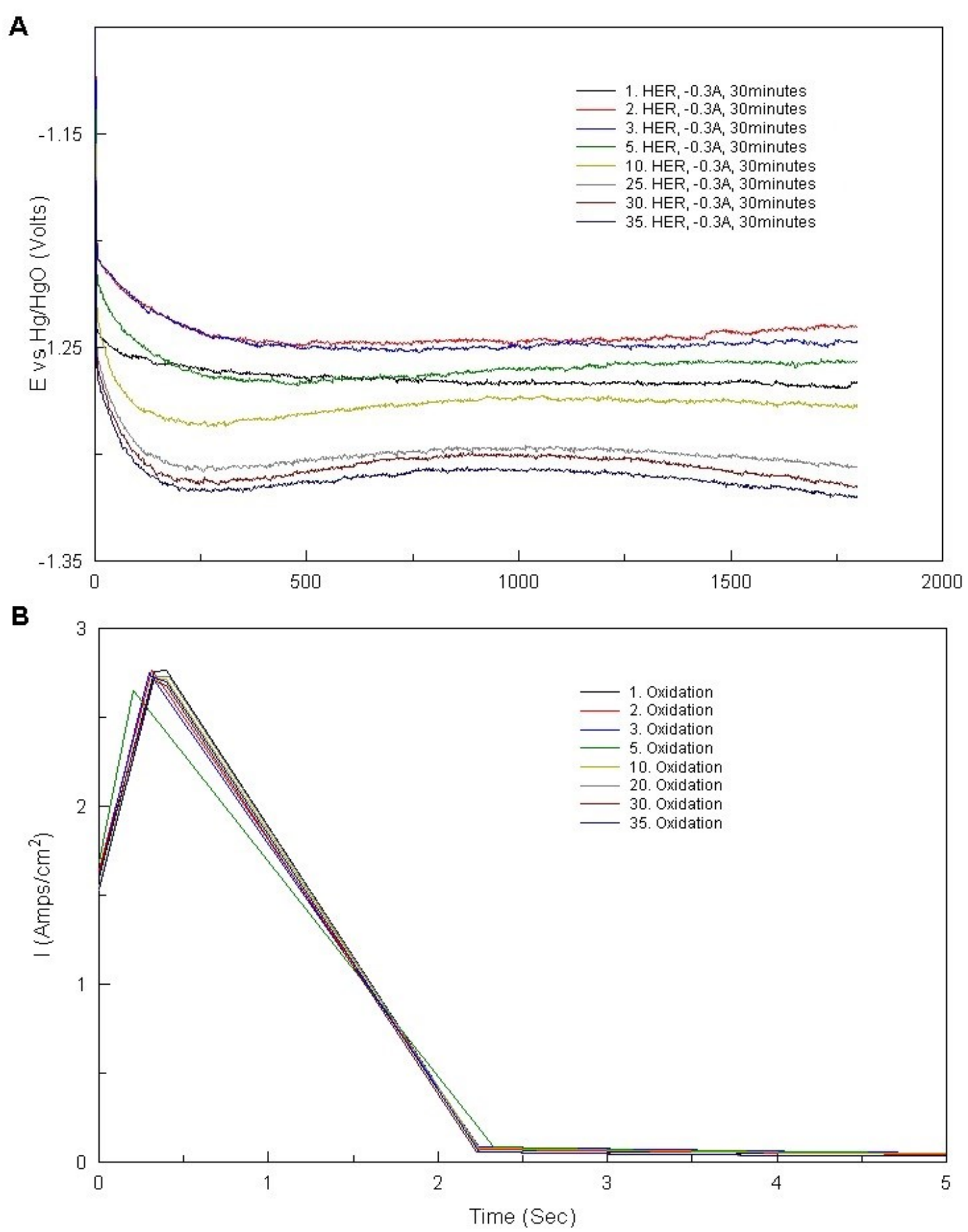

Figure 4. A - Operation of 100 um electrode sample under current density of $-0.3 \mathrm{~A} / \mathrm{cm}^{2}$, within subsequent cycles separated with oxidation process, $B$ - Oxidation currents for every cycle at -0.2 Votential 

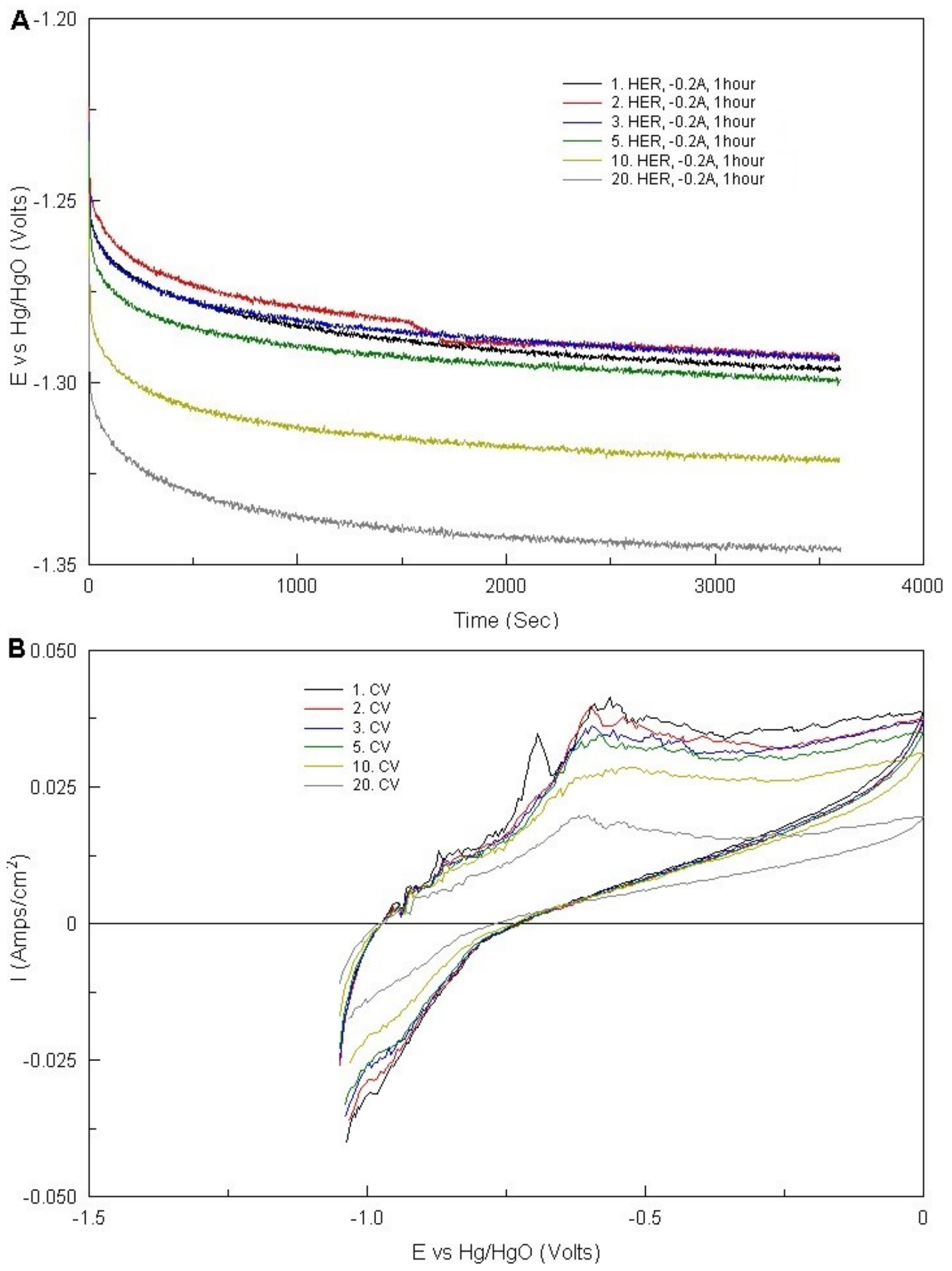

Figure 5. A-Registered voltage change under $200 \mathrm{~mA} / \mathrm{cm}^{2}$ current density, B - Comparison of cyclic voltammograms registered after each cycle 


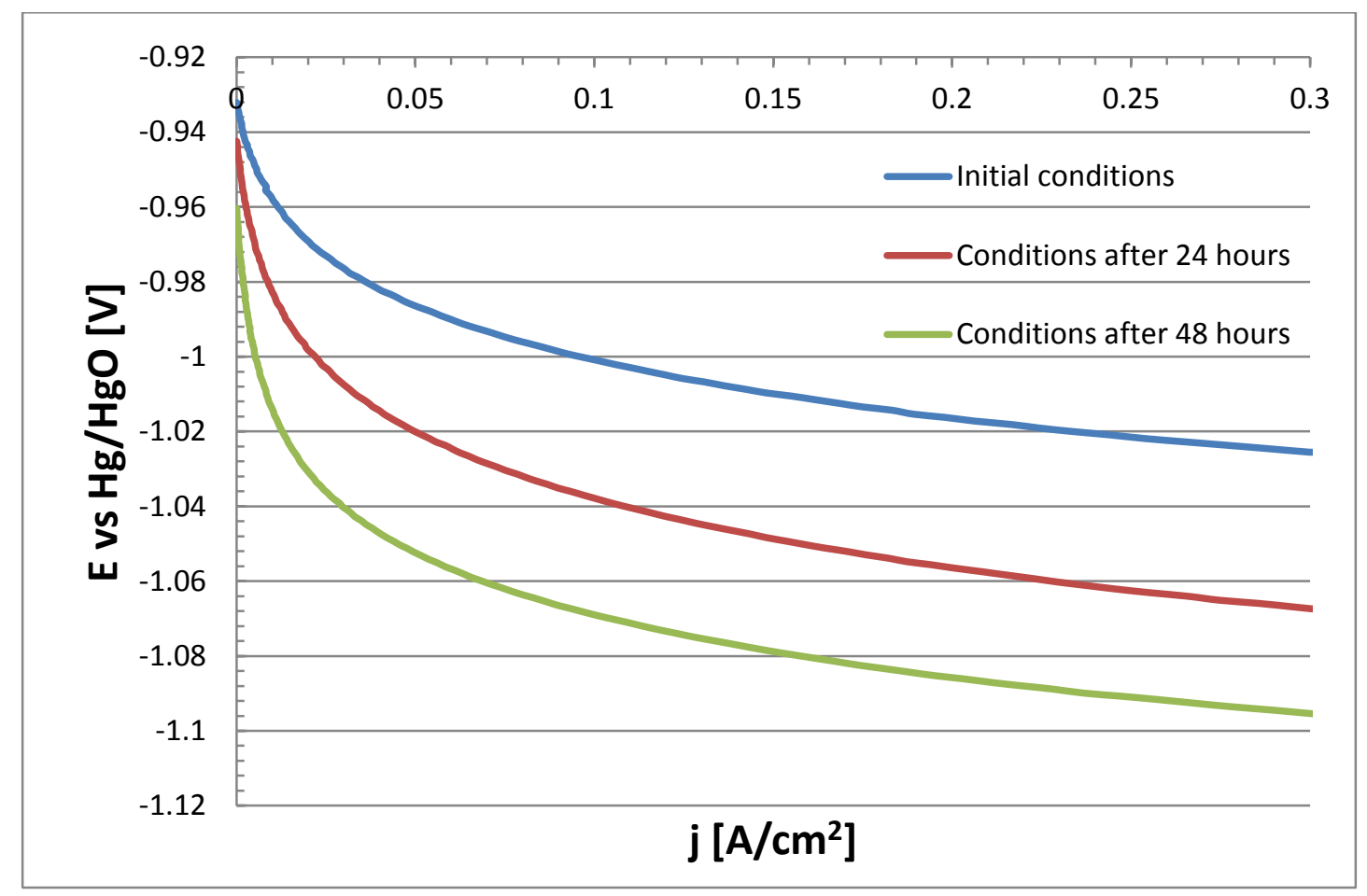

Figure 6. Potential (Current density) curve of operated sample initially, after 24 and 48 hours 


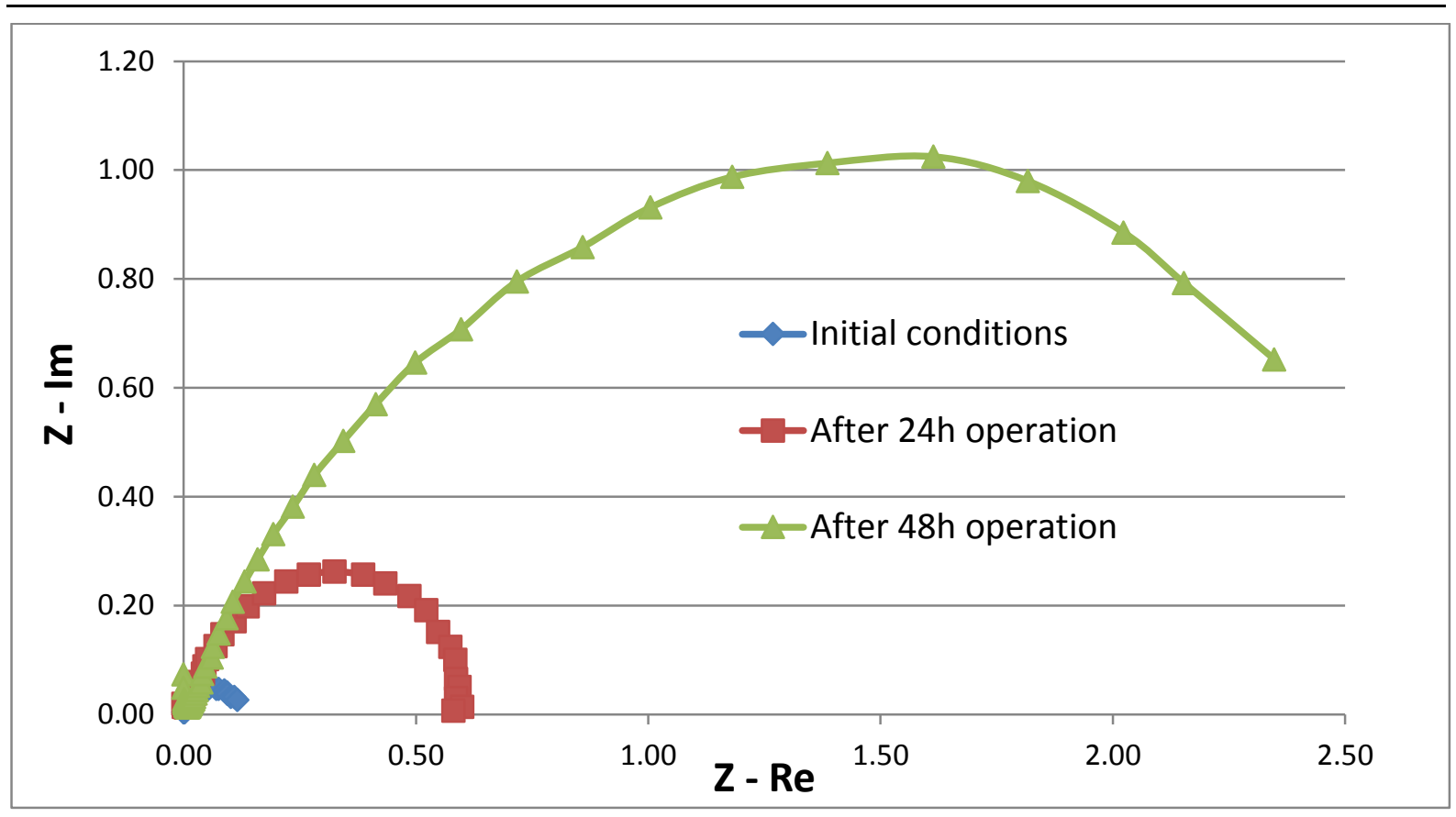

Figure 7. Nyquist plots for the sample at initial conditions, after 24 and 48 hours of operation at $-1.05 \mathrm{~V} v \mathrm{~s} \mathrm{Hg} / \mathrm{HgO}$ potential 


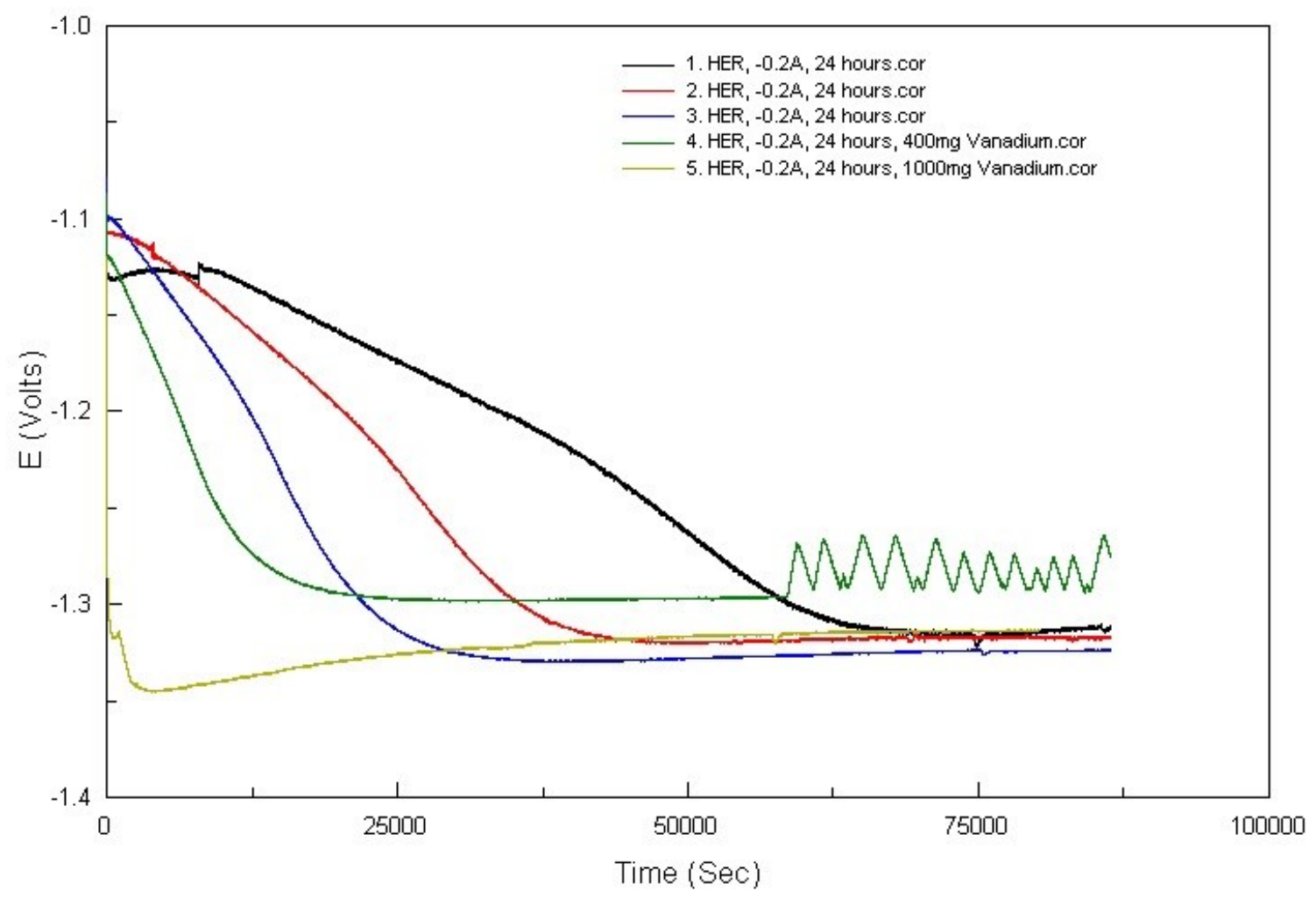

Figure 8. Comparison of the time effect of vanadium influence for Raney nickel cathode performance 


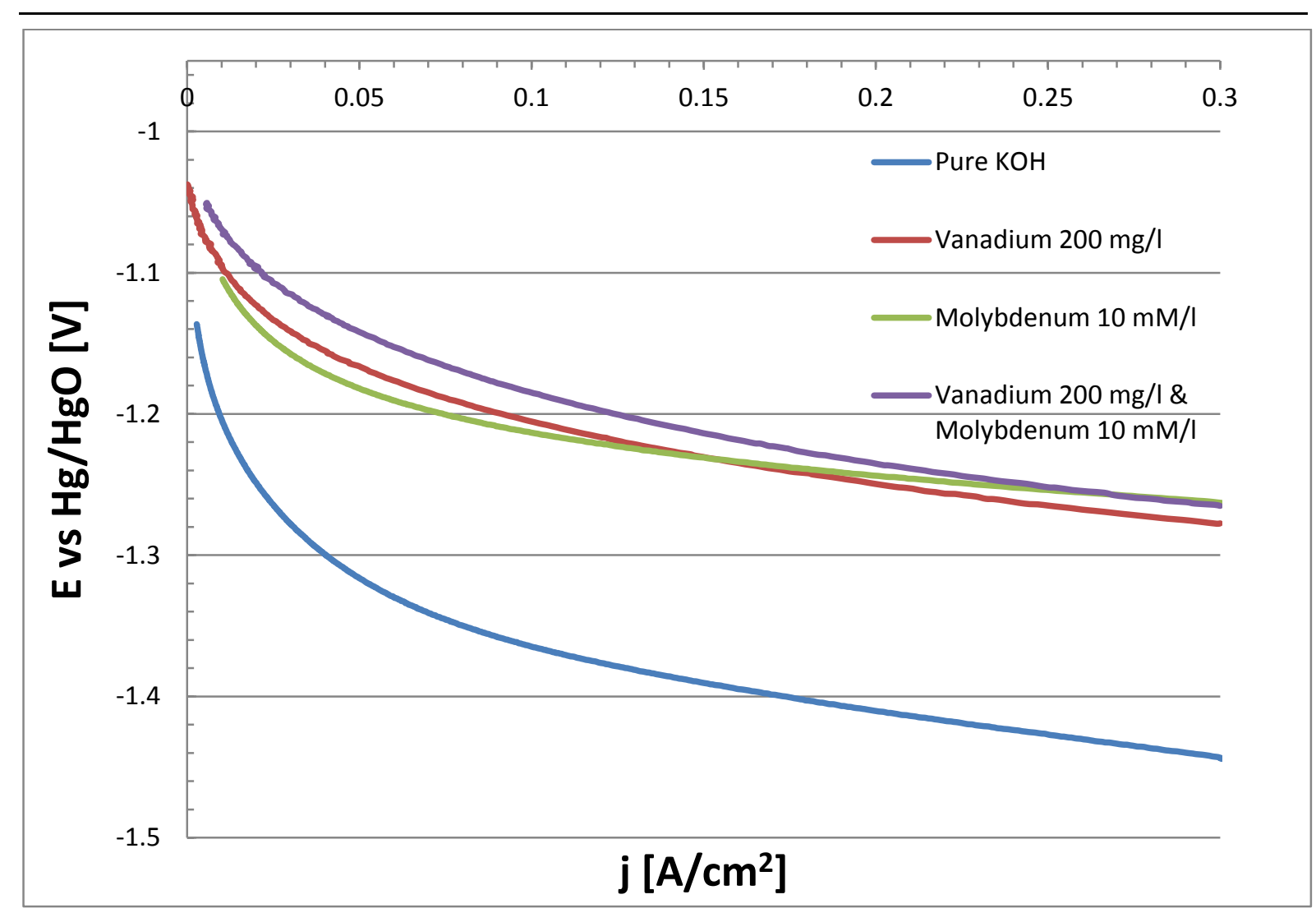

Figure 9. Comparison of the performance of Raney nickel electrodes deactivated by hydrides in pure KOH electrolyte and with addition of vanadium and/or molybdenum compounds 
A

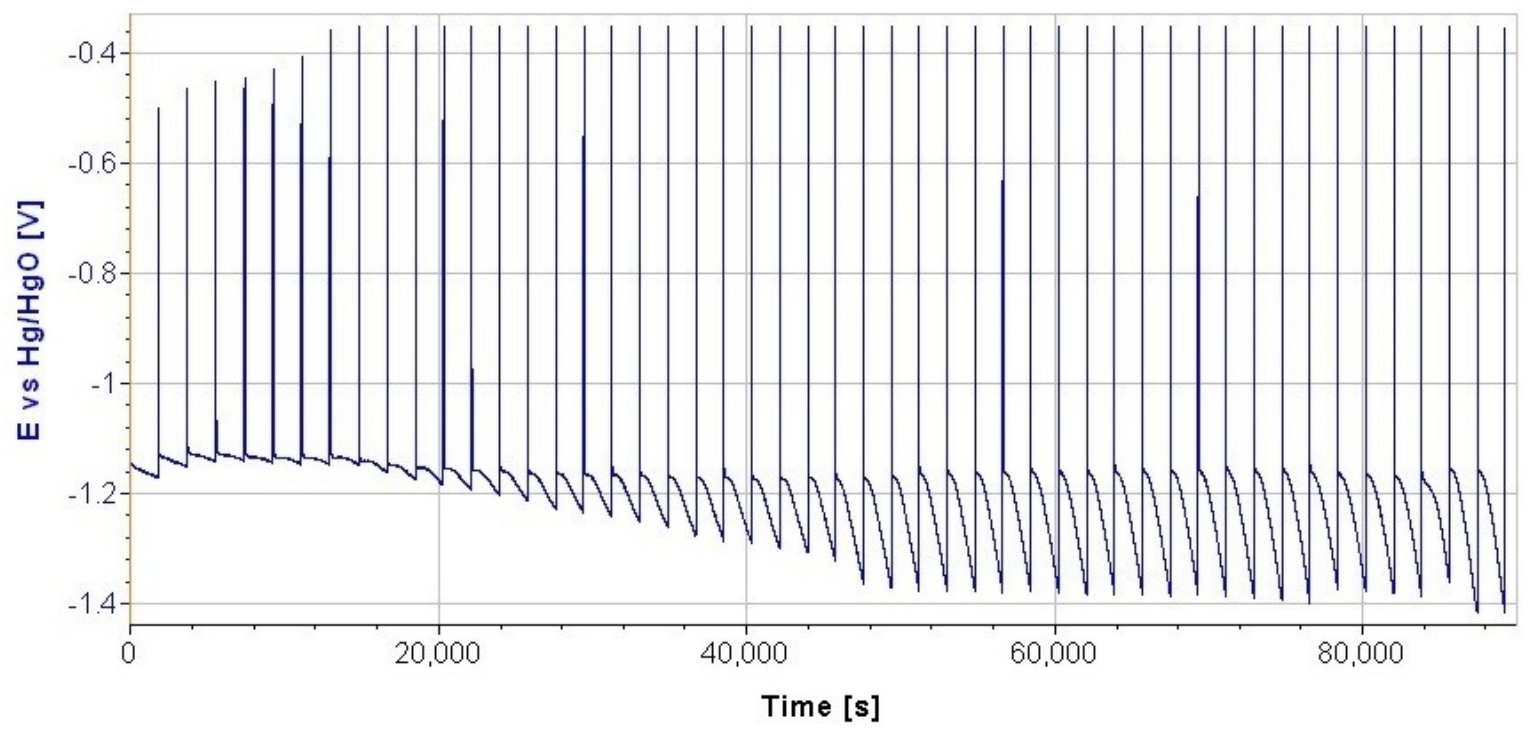

B

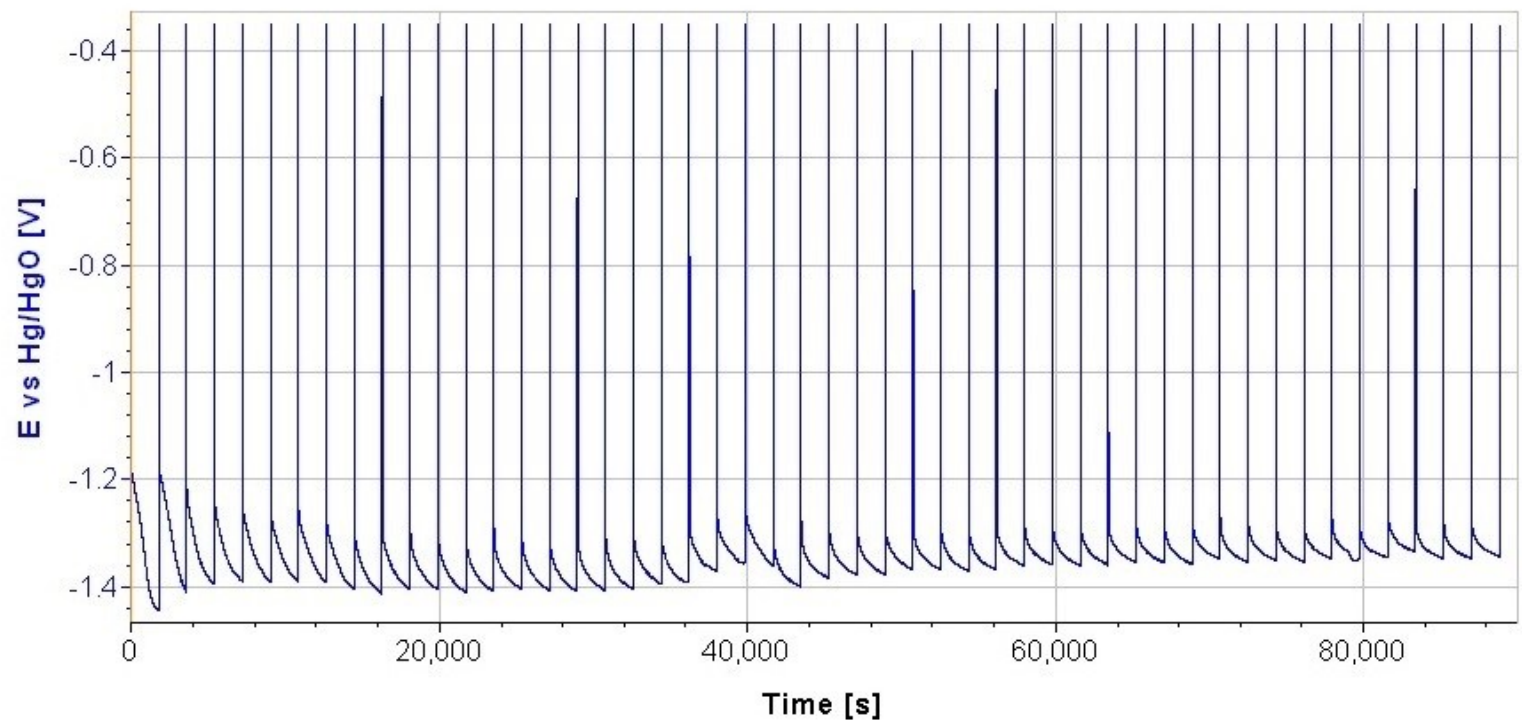

Figure 10. A - Deactivation of Raney nickel electrode in stable load with oxidation cycles,

$B$ - Reactivation of Raney nickel electrode in stable load with oxidation cycles after adding vanadium to the electrolyte 
A

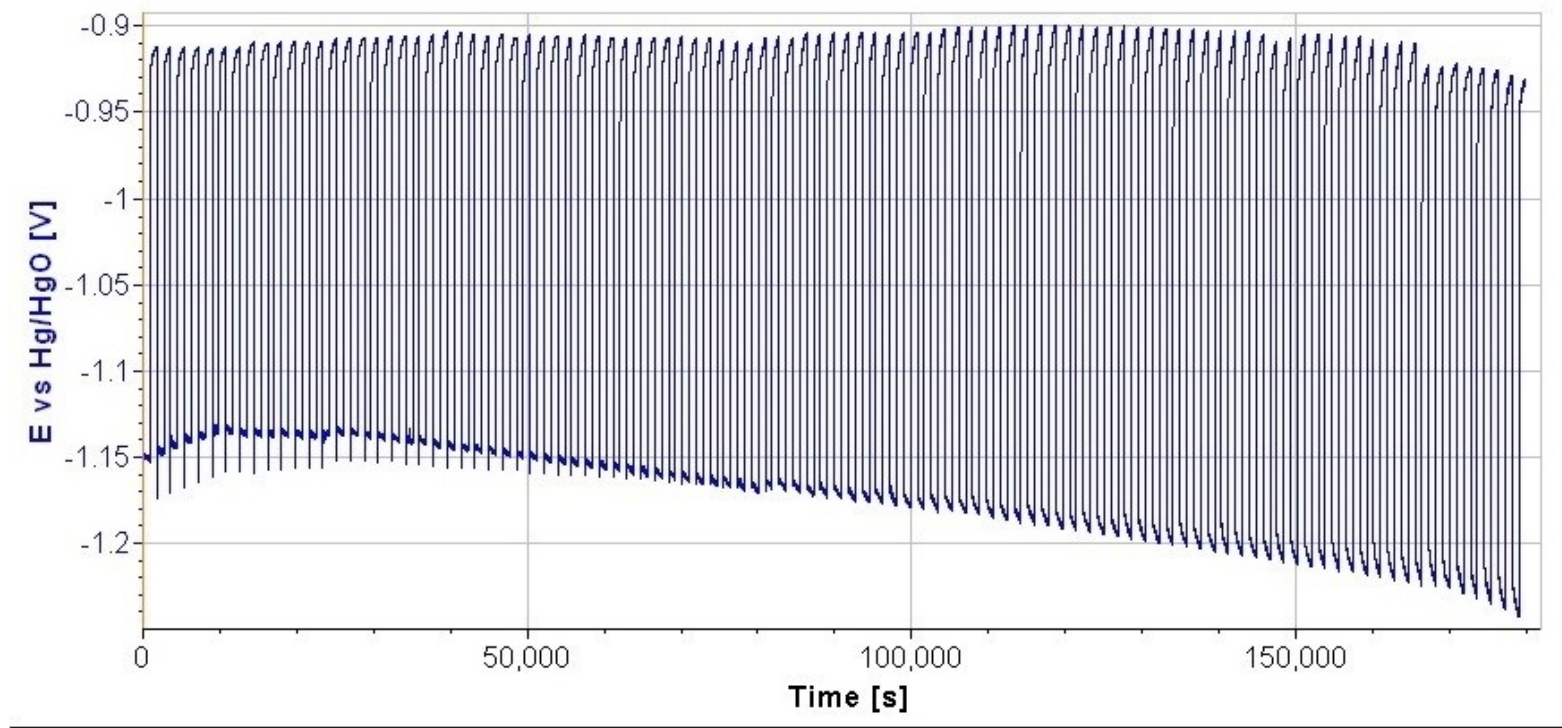

B

- final conditions _ initial conditions

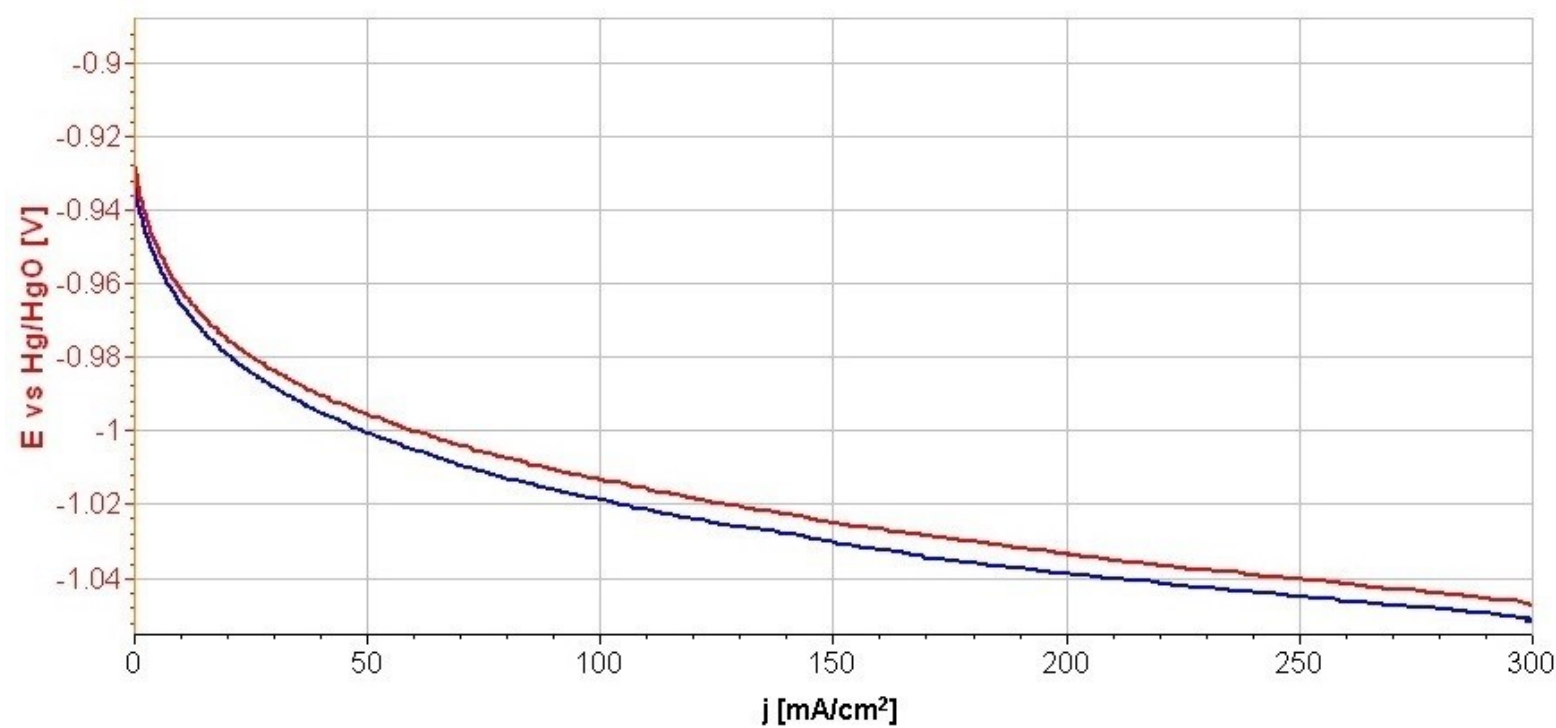

Figure 11. Intermittent operation influence on Raney Nickel Sample, A-Potential in a function of time, B-Electrodes Potential (Current density) curves before and after intermittent operation cycle 
A

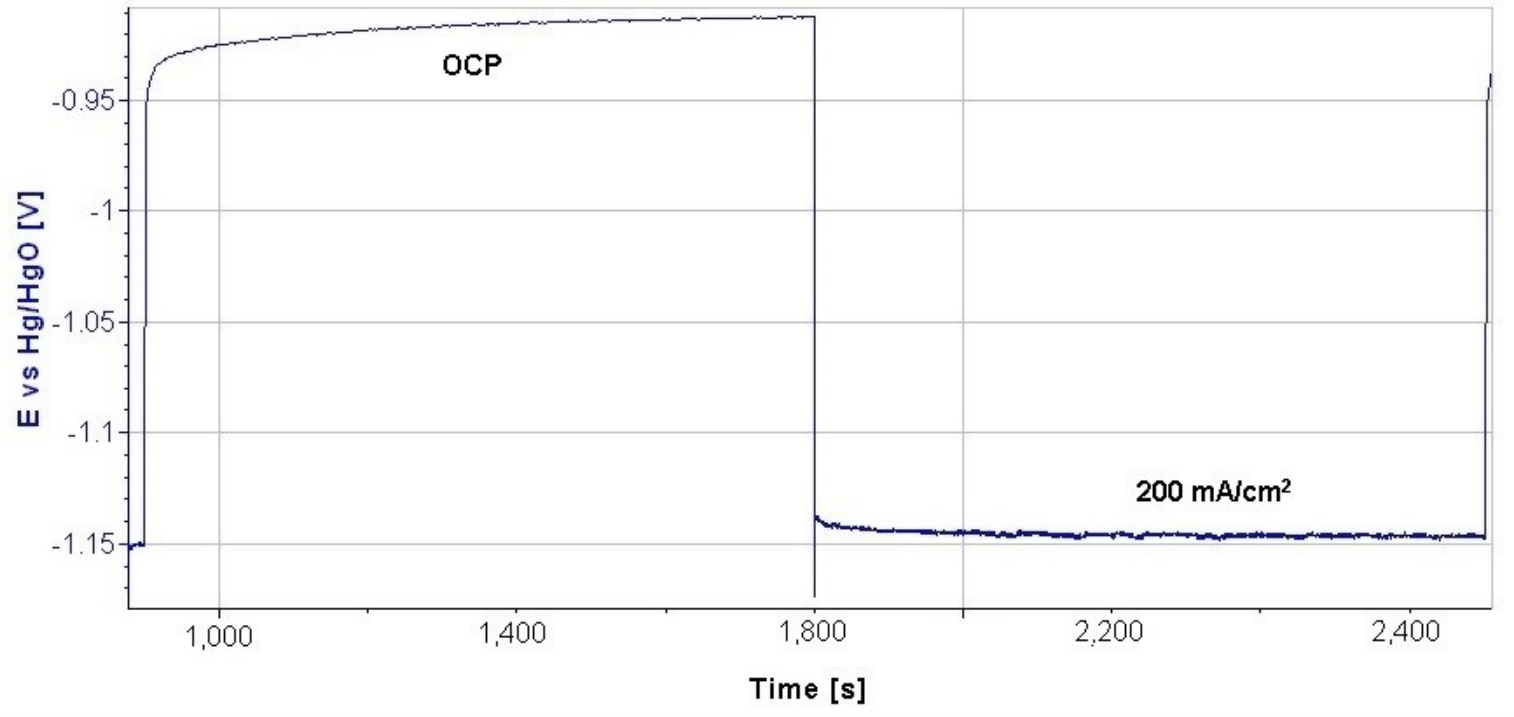

B

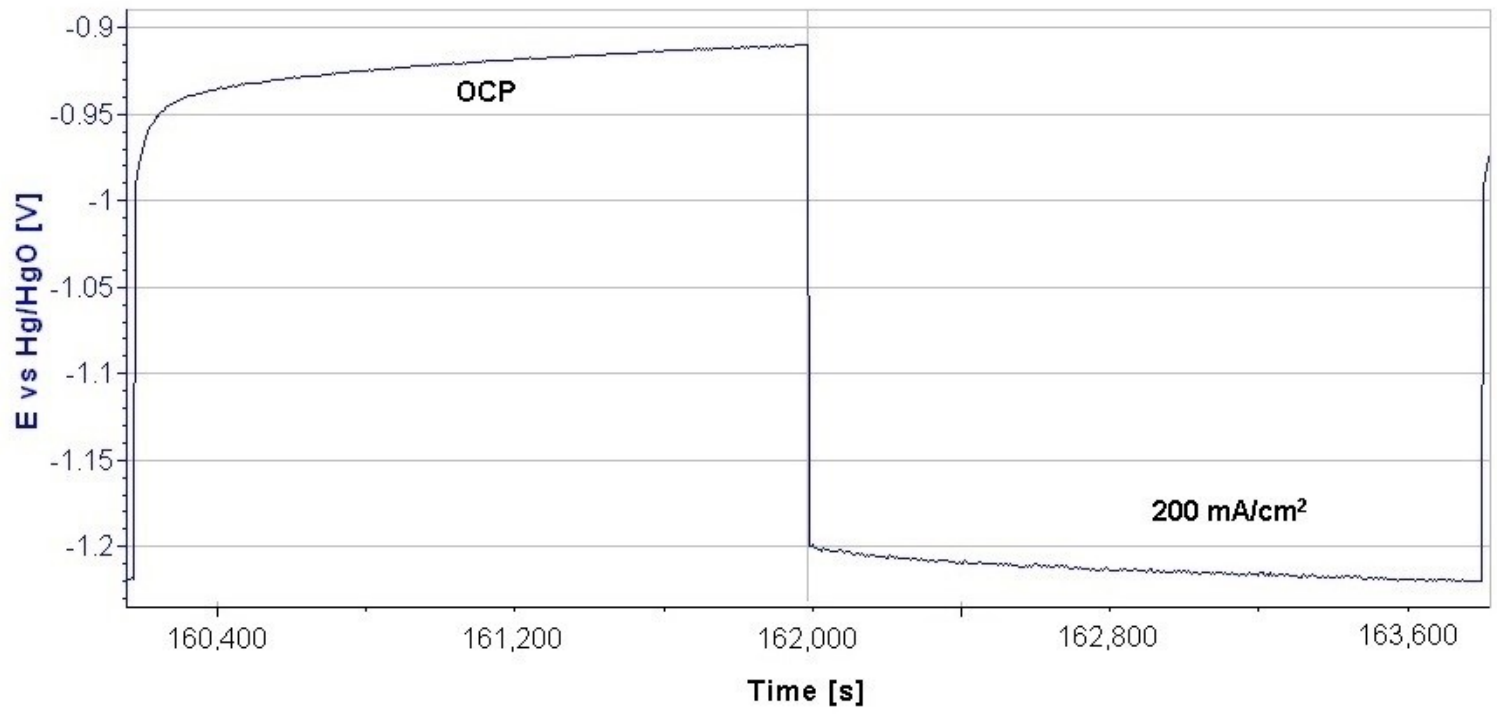

Figure 12. Comparison of $5^{\text {th }}(A)$ and $90^{\text {th }}(B)$ cycles during intermittent load operation 


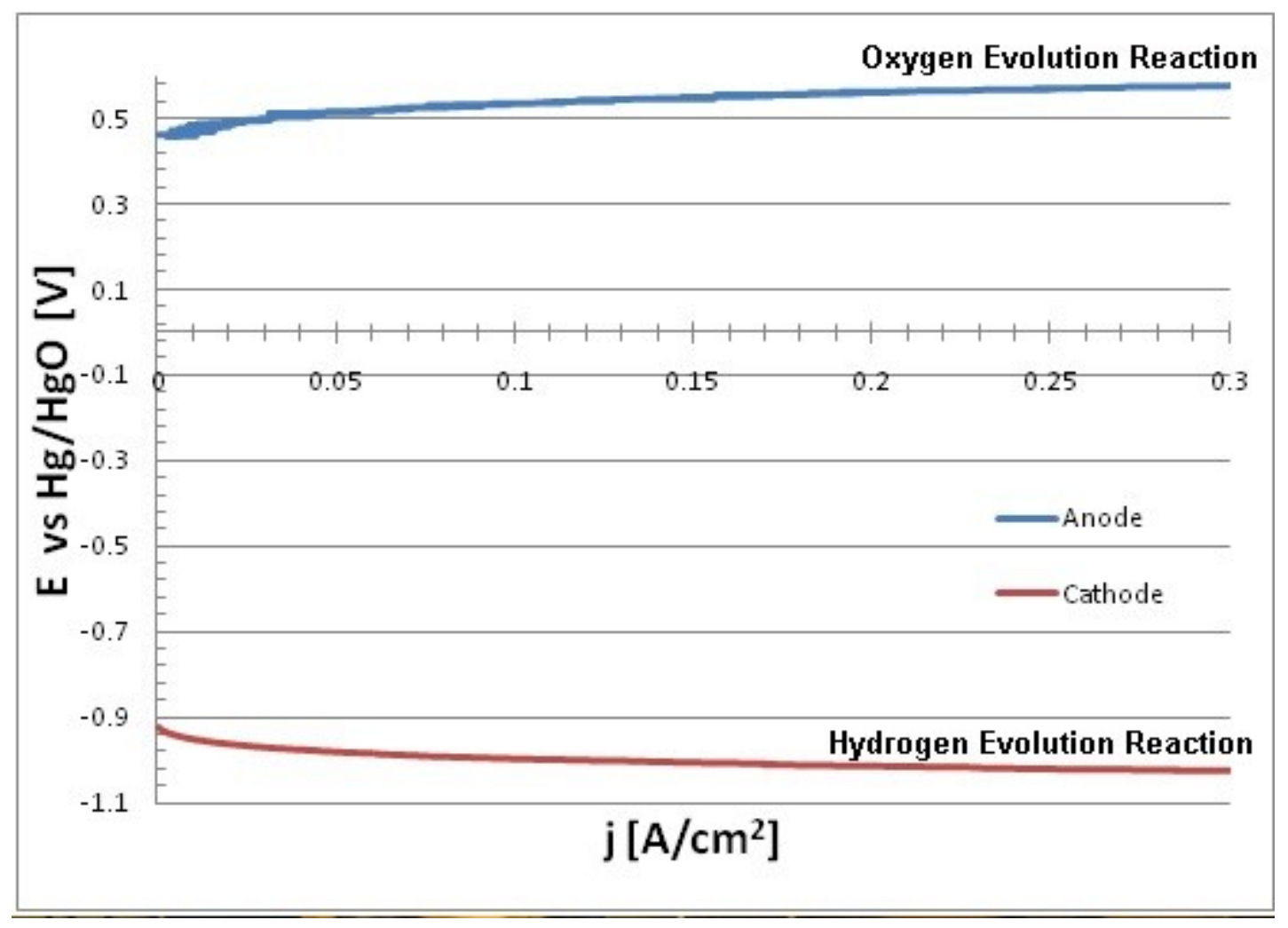

Figure 13. Potential (Current density) curves for cathode and anode 


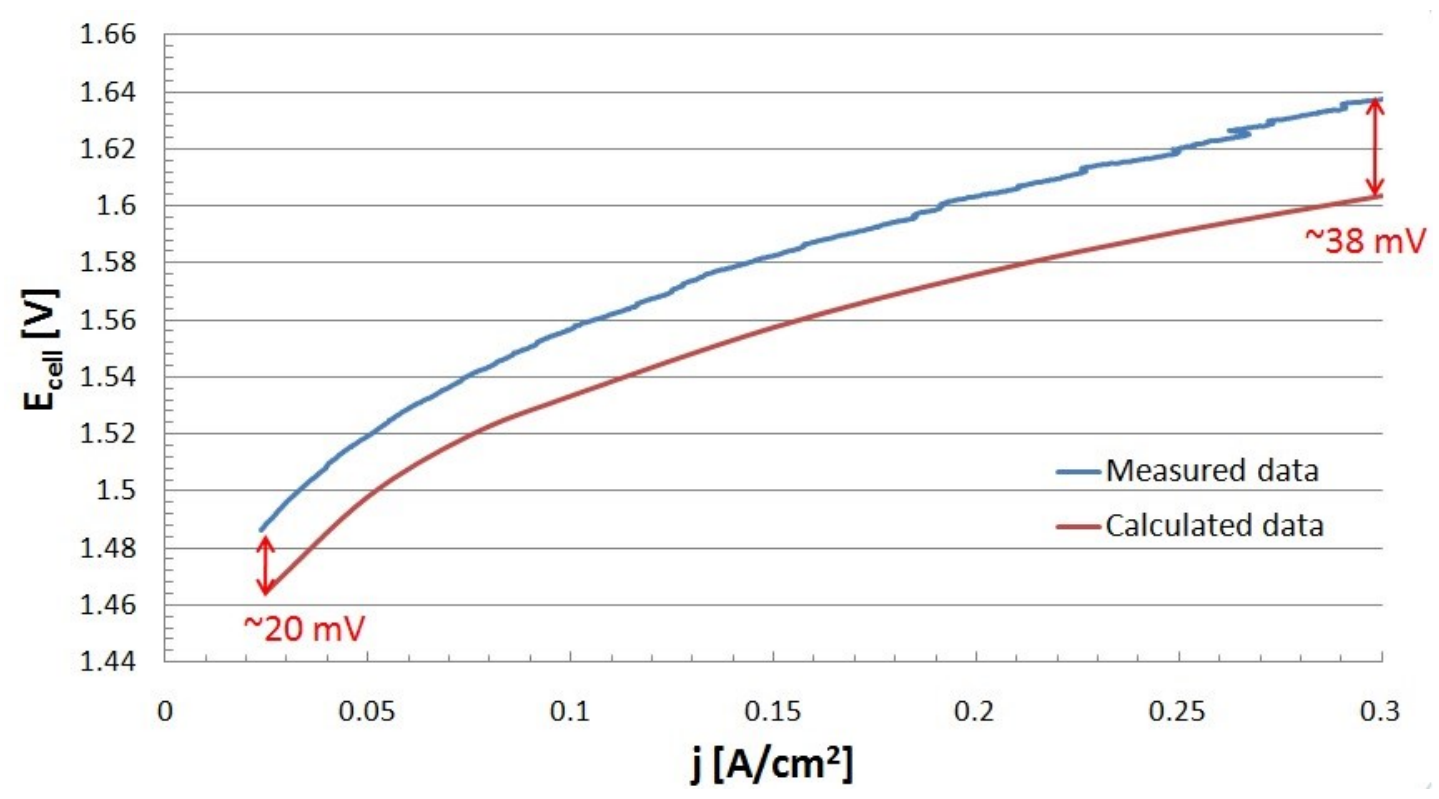

Figure 14. Comparison measured and theoretically calculated data for single cell - initial conditions 
A $-1^{\text {st }}$ cycle $\quad-2^{\text {nd }}$ cycle

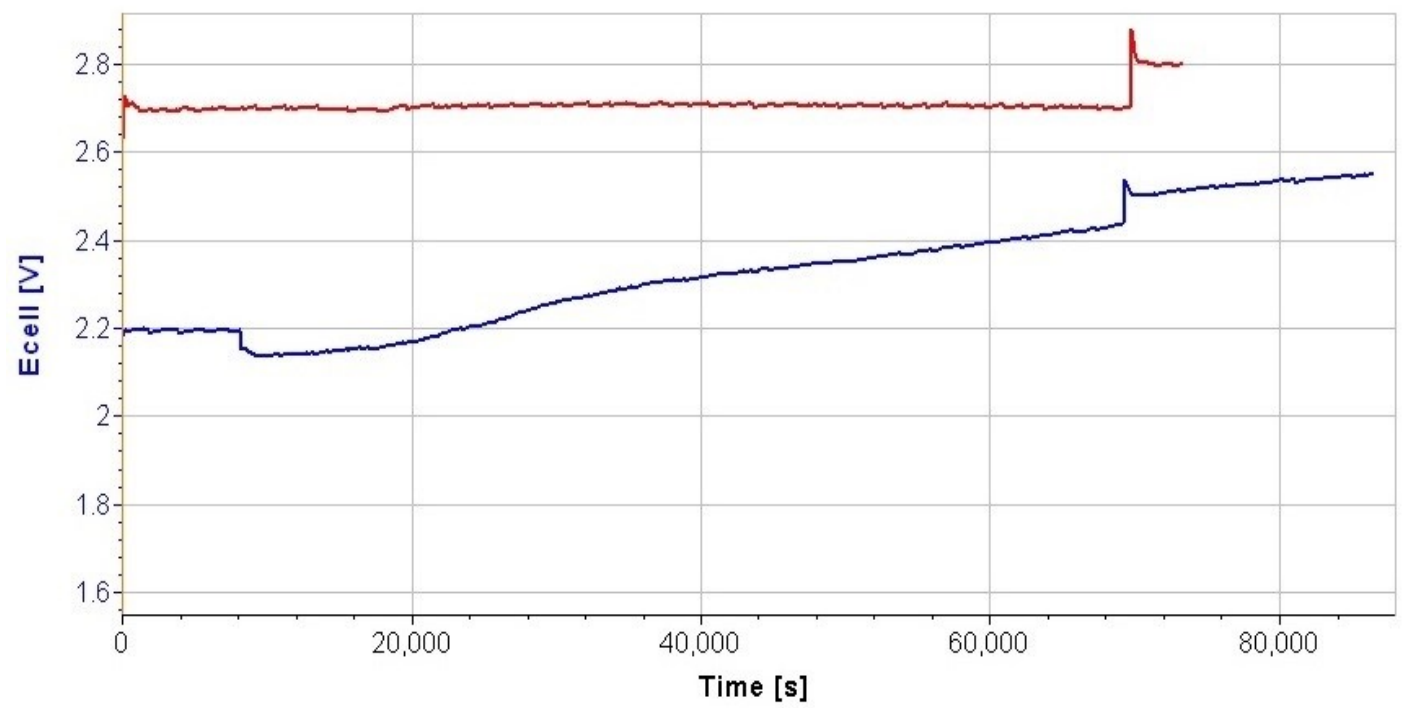

B $\quad$ - initial conditions $\quad$ performance after $2^{\text {nd }}$ cycle $\quad$ - performance after $1^{\text {st }}$ cycle

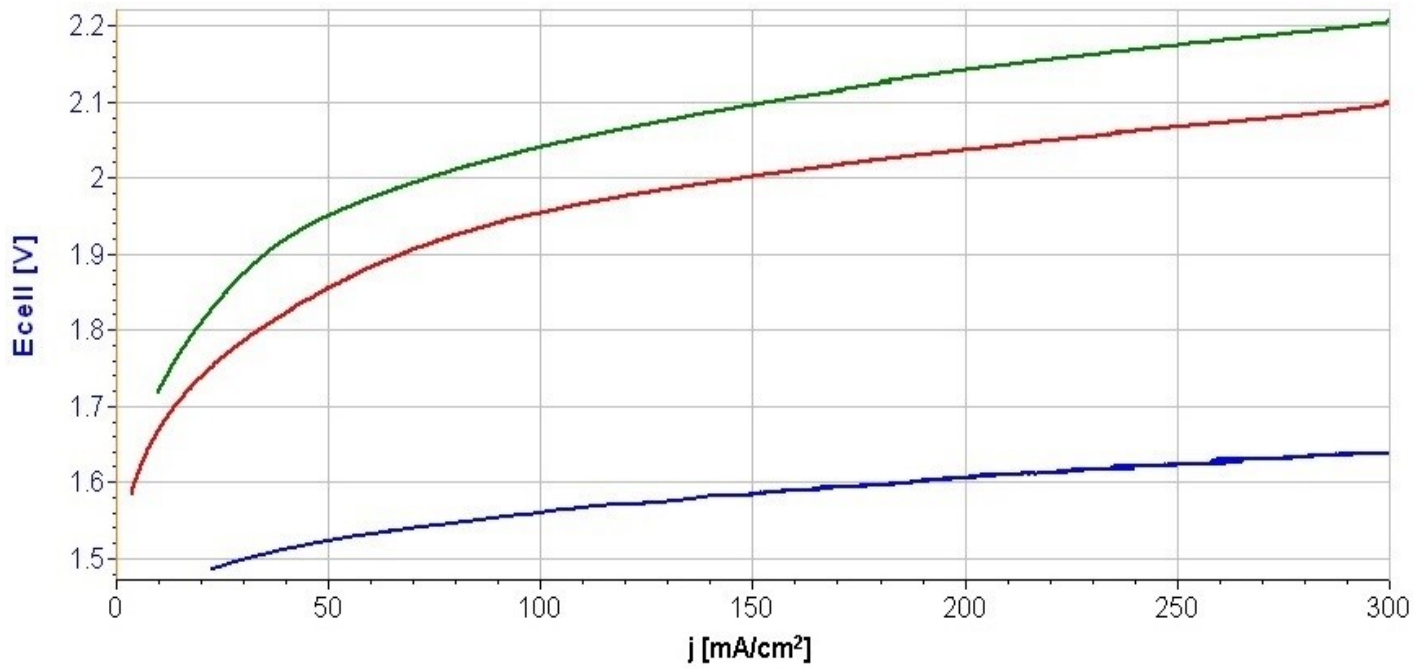

Figure 15. A-Registered voltage change during $1^{\text {st }}$ and $2^{\text {nd }}$ cycle operation under 200 $\mathrm{mA} / \mathrm{cm}^{2}$ current density, B - Comparison of Potential (Current density) curves of single cell at initial conditions, after $1^{\text {st }}$ cycle and after $2^{\text {nd }}$ cycle 
Tables:

\begin{tabular}{|c|c|c|}
\hline \multicolumn{3}{|c|}{ Initial sample conditions } \\
\hline $\mathrm{E}[\mathrm{V}]$ & $\mathbf{R}_{\mathrm{ct}}\left[\Omega^{*} \mathrm{~cm}^{2}\right]$ & $C_{d l}\left[F / \mathrm{cm}^{2}\right]$ \\
\hline-0.95 & 0.989 & 0.160 \\
\hline-1.00 & 0.206 & 0.099 \\
\hline-1.05 & 0.127 & 0.074 \\
\hline-1.10 & 0.101 & 0.065 \\
\hline-1.15 & 0.097 & 0.062 \\
\hline \multicolumn{3}{|c|}{$\begin{array}{c}\text { Sample conditions after } 24 \text { hours operation with } 0.3 \mathrm{~A} \\
\text { oxidation every hour }\end{array}$} \\
\hline $\mathrm{E}[\mathrm{V}]$ & $\mathbf{R}_{\mathrm{ct}}\left[\Omega^{*} \mathrm{~cm}^{2}\right]$ & $\mathrm{C}_{\mathrm{dl}}\left[\mathrm{F} / \mathrm{cm}^{2}\right]$ \\
\hline-0.95 & 5.312 & 0.058 \\
\hline-1.00 & 0.987 & 0.038 \\
\hline-1.05 & 0.588 & 0.016 \\
\hline-1.10 & 0.363 & 0.013 \\
\hline-1.15 & 0.255 & 0.011 \\
\hline \multicolumn{3}{|c|}{$\begin{array}{c}\text { Sample conditions after } 48 \text { hours operation with } 0.3 \mathrm{~A} \\
\text { oxidation every hour }\end{array}$} \\
\hline$E[V]$ & $\mathbf{R}_{\mathrm{ct}}\left[\Omega^{*} \mathrm{~cm}^{2}\right]$ & $\mathrm{C}_{\mathrm{dl}}\left[\mathrm{F} / \mathrm{cm}^{2}\right]$ \\
\hline-0.95 & 18.39 & 0.061 \\
\hline-1.00 & 10.25 & 0.058 \\
\hline-1.05 & 2.95 & 0.039 \\
\hline-1.10 & 0.77 & 0.016 \\
\hline-1.15 & 0.43 & 0.011 \\
\hline
\end{tabular}

Table 1. EIS parameters for $100 \mu \mathrm{m}$ sample just after activation and after 24 hours and 48 hours operation 